\title{
Presplit Blasting Technique in Treating Hard Overlying Strata: From Numerical Simulation to Field Practice
}

\author{
Baisheng Zhang $\mathbb{C}^{1,2}$ Zhiping Yang, ${ }^{1}$ Xuming Yang, ${ }^{3}$ and Shuai Zhang ${ }^{4}$ \\ ${ }^{1}$ College of Mining Engineering, Taiyuan University of Technology, Taiyuan, Shanxi 030024, China \\ ${ }^{2}$ Shanxi Province Research Centre of Green Mining Engineering Technology, Taiyuan, Shanxi 030024, China \\ ${ }^{3}$ Xinjin Company, Huayang New Material Technology Group Co., Ltd., Yangquan, Shanxi 045000, China \\ ${ }^{4}$ Department of Construction Development, Jinneng Holding Equipment Manufacturing Group, Jincheng, Shanxi 048000, China
}

Correspondence should be addressed to Baisheng Zhang; bszhang2021@163.com

Received 23 January 2021; Revised 28 March 2021; Accepted 22 April 2021; Published 4 May 2021

Academic Editor: Jia Lin

Copyright (c) 2021 Baisheng Zhang et al. This is an open access article distributed under the Creative Commons Attribution License, which permits unrestricted use, distribution, and reproduction in any medium, provided the original work is properly cited.

\begin{abstract}
The potential dynamic risk of the mined underground space with hard overlying strata is one of the main concerns for coal operators. This paper presents a comprehensive study on treating the hard overlying strata upon the coal seam through the presplit blasting technique. The properties of the overlying strata were firstly investigated and evaluated via the laboratory tests and theoretical analysis. With the consideration of the geological and mining condition of the research area, the critical parameters of the presplit blasting technique (e.g., unsaturation coefficient, borehole spacing, and the slit width) were consequently determined via the numerical simulation with the application of LS-DYNA. Then, the field practice in accordance with the determined parameters was carried out in Yuwu coal mine. The effectiveness of the presplit blasting technique was well verified when the microstructures of the surrounding rock were investigated. The success presented in this paper does not only demonstrate the feasibility of using the presplit blasting technique in treating the hard strata of underground mines but also provide a guideline in determining the critical parameters by the numerical simulation and theoretical analysis from the design aspect.
\end{abstract}

\section{Introduction}

It has been well noted that the hard overlying strata, which are also termed the hard roof upon the coal seams, are generally defined as the key strata by strata controlling engineers [1-4]. Different from other strata around the coal seam, the hard overlying strata generally consist of one or more layers of thick and strong strata (e.g., limestone or sandstone). The hard overlying strata will be hung for a long time rather than immediately be crushed and collapsed with the excavation process. During the past decades, a large amount of reported rock burst and coal and gas outburst accidents are attributed to the existence of these exposed and hung hard overlying strata after the extraction of coal resource [5-7]. The main reason for these unexpected dynamic accidents is that the concentrated stress and accumulated energy released within a very short time, once the hung roof cannot sustain its integrity [8]. The dynamic accidents associated with the large deformation of surrounding rock and the severe damages of support structures even the injuries to miners have attracted much attention either from the academic researchers or the on-site managers $[9,10]$. In addition, the sudden roof falls will result in the accumulation of gas and $\mathrm{CO}$ emission, leading to some other potential risks for underground coal operators [8]. How to effectively control or treat the hard overlying strata therefore becomes an urgent issue to be considered.

There are numerous underground coal mines facing the problematic issues in terms of the management of the hard overlying strata and the related dynamic accidents. From the design aspect, pretreating the hard overlying strata to weaken its strength and reduce the hung length is believed to be one of the most effective methods [11,12]. Different pretreating techniques have been proposed and put into 
practical applications to eliminate or prevent associated dynamic accidents caused by the exposed hard overlying strata. Among them, the presplit blasting technique (see Figure 1) and the hydraulic-fracturing technique are believed to be two most popular methods for weakening the hard overlying strata $[8,12-15]$.

The main aim of either the hydraulic-fracturing technique or the presplit blasting technique in treating the hard overlying strata is to generate a series of manmade cracks or fractures [16-18]. In practice, it is not very easy to maintain the accurate application of hydraulic fractures/cracks and therefore the effect of which will be somehow affected. Compared with the hydraulic-fracturing technique, the presplit blasting technique in treating the hard overlying strata obtains its comparative advantages including (1) ease of logistics, the requested equipment is with acceptable configurations and it is thus very suitable to be used in the narrow space in underground, when it is compared with the hydraulic-fracturing technique [8]; (2) cost effectiveness; and (3) the universal feasibility, which can be used to pretreat different types of hard overlying strata $[8,12]$. Most importantly, the presplit blasting technique is believed to be the controllable method as verified from different practical applications in variable coal mines.

Currently, the application of the presplit blasting technique in weakening the hard overlying strata has been widely accepted, from which the critical parameters including the layout and depth of the blast holes, the usage of cartridge, and the design of associated support system are well recognized. The numerical modelling method has also been adopted to determine the final design of the presplit blasting technique. Different computing programmes (e.g., ABAQUS, ANSYS, etc.) have shown their superior advantages in numerical simulation of the presplit blasting technique [19-21], based on which the preliminary design can be proposed with some assumptions. Note that the surrounding rock is heterogeneous in nature; the results obtained from the finite element numerical simulation should be used together with the field investigation before the final design.

Previous research on the presplit blasting technique has provided the meaningful guideline for further applications of pretreating hard overlying strata. However, there are still some research gaps that should be investigated: (1) the comprehensive study on the presplit technique in different types of the roadway (e.g., large-scale cross section) is still requested; (2) the in-depth evaluation of the preblasting technique, from the initial proposal to the final design, should also be further conducted.

Against this background, the comprehensive research with the combined numerical simulation and field test was conducted on the representative coal mine operated by Luan Coal Ltd., China. Different from previous research, the effectiveness of the large-scale cross section cut-through of the underground mine is investigated. This paper starts with the concise introduction of the geological and mining conditions of the selected coal mine, followed by the numerical modelling covering the large range of parametric studies. This paper ends up with the case study with the application of the critical parameters obtained from the comprehensive

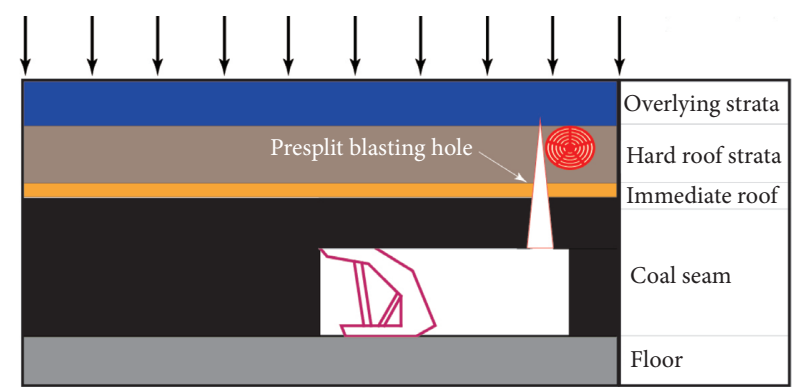

FIgURE 1: The sketch of the presplit blasting technique in treating the hard roof.

research. As expected, using the presplit blasting technique in weakening the hard overlying strata exhibited the superior advantages.

\section{Geological and Mining Conditions}

The N1202 longwall of Yuwu coal mine, located in Shanxi province China, was selected to verify the effectiveness of the presplit blasting technique in weakening the hard overlying strata. As depicted in Figure 2, the N1202 longwall is surrounded by the N1201 and N1203 longwall, the southern of which is the unmined coal seam. The width and the strike length of N1202 longwall are $295 \mathrm{~m}$ and $890 \mathrm{~m}$, respectively. The average buried depth of investigated area ranges from 515 to $544 \mathrm{~m}$. The 6.34-meter-thick coal seam numbered 3\# is extracted by the top caving method with a mining depth of $3 \mathrm{~m}$. The average dip angle of the coal seam is $6^{\circ}$. The black coal seam is in danger of explosion and outburst with a gas content of $10.05 \mathrm{~m}^{3} / \mathrm{t}$.

Figure 3 presents the lithology of the N1202 longwall, in which there is an 8.10-meter-thick medium sandstone located upon the coal seam. According to the definition of the hard roof presented earlier, this medium sandstone can be regarded as the hard roof of N1202 longwall. Due to the existence of the hard overlying strata and the high-strength bolting system, the medium sandstone within the longwall is hung without obvious deformation observed, which is the other evidence to support the correction of the definition mentioned above.

The systematic laboratory tests were conducted to determine the mechanical properties of the surrounding rocks. These rock samples were collected through the drilling hole and then cut into the standard samples with a diameter of $50 \mathrm{~mm}$ and a height of $100 \mathrm{~mm}$ for compression tests in accordance with ASTM D7012-10 [22]. For tensile tests, the rock samples with a diameter of $50 \mathrm{~mm}$ and a height of $25 \mathrm{~mm}$ were also tested. Note that the values listed in Table 1 were all averaged from three identical specimens from each group.

It is apparent in Table 1 that the compressive strength of the overlying stratum upon the coal seam (e.g., sandy mudstone and fine sandstone) is much higher. Based on the mechanical properties of rock samples presented in Table 1 and the key strata theory proposed by Qian et al. [23], the length of the initial crushed hard roof can be then calculated by the following equation: 


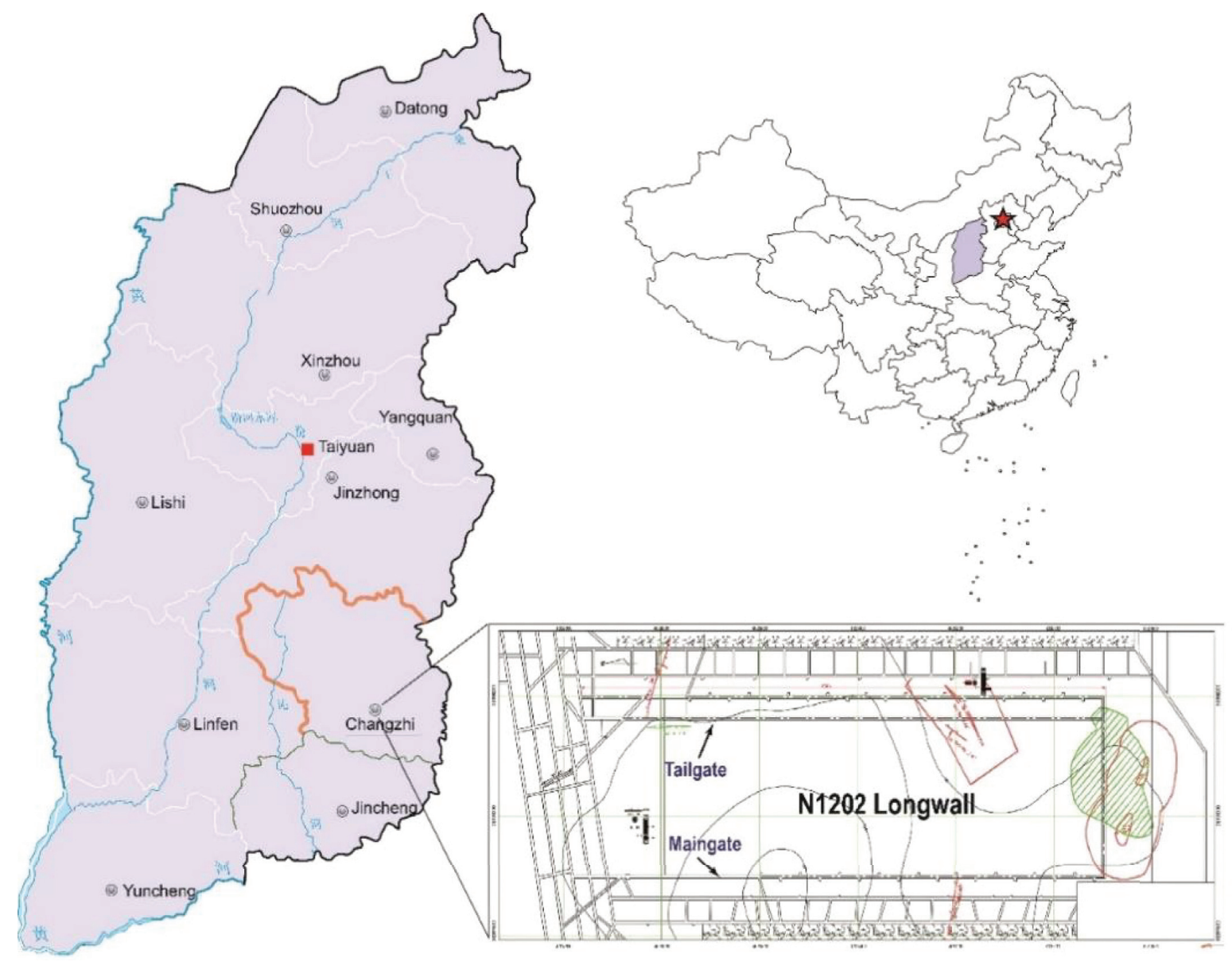

FIgURE 2: Geographical location and the plane view of the N1202 longwall.

$$
L_{m}=\frac{L}{\sqrt{2} l_{m}} \sqrt{L^{2}-\sqrt{L^{4}-4 l_{m}^{4}}}=48.59 \mathrm{~m},
$$

in which $L_{m}$ is the theoretical length of the crushed block, $L$ is the length of the longwall, and $l_{m}$ is defined as the length of the secondary key strata. The calculated length of the hung roof is about $50 \mathrm{~m}$, and thus, it is urgent to take some measure to treating the hard roof from the perspective of controlling the stability of the surrounding rock.

To maintain the stability of the surrounding rock of N1202 longwall, the 8300-millimeter-length cables were installed associated with the blotting support system, the sketch of which can be seen in Figure 4. Note that the predriving roadway was excavated twice (Step 1 and Step 2); the GFRP bolts were installed in the working face. The additional support reinforcement increases the difficulty of the collapse of the hard roof, and thus, the presplit blasting technique is proposed to treat the hard roof strata by changing the integrity of the overlying strata.

\section{Numerical Simulation}

The embedded programme in the LS-DYNA covers the advantages of both Euler and Lagrange's algorithms, which is actually suitable to simulate the coupling of the fluid-solid coupling (e.g., the propagation process of the detonation shock wave and the flow of the blasting gas). In this programme, the Euler algorithm is generally used to divide the internal cell grid whereas the boundary of the built model was usually achieved by the Lagrange algorithm. To prevent the occurrence of unexpected distortion of the grid, the division of the target zone should be manually adjusted. More detailed information about both the theoretical foundation and setup of the model can be found in the manual of the of LS-DYNA [24].

Figure 5 depicts the distribution of different zones of surrounding rock with the use of the presplit blasting technique. According to the propagation of the explosive energy, the surrounding rock around the blast hole can be divided into the crushed zone and the fractured zone. The explosive energy is initially generated around the surface of the blast hole and some of them will be consumed to crush the surrounding rock, leading to the generation of the crushed zone. With the shock waves gradually attenuating into stress waves, the original quasistatic pressure enlarges the initial cracks. If the peak intensity of the shock wave is larger than that of the compressive strength of the surrounding rock, the blast hole will be directly damaged and crushed. The radius of the crushed zone (i.e., $R_{1}$ ) can be marked from the numerical simulation if the monitored strength applied to the surrounding rock exceeds its peak strength. 


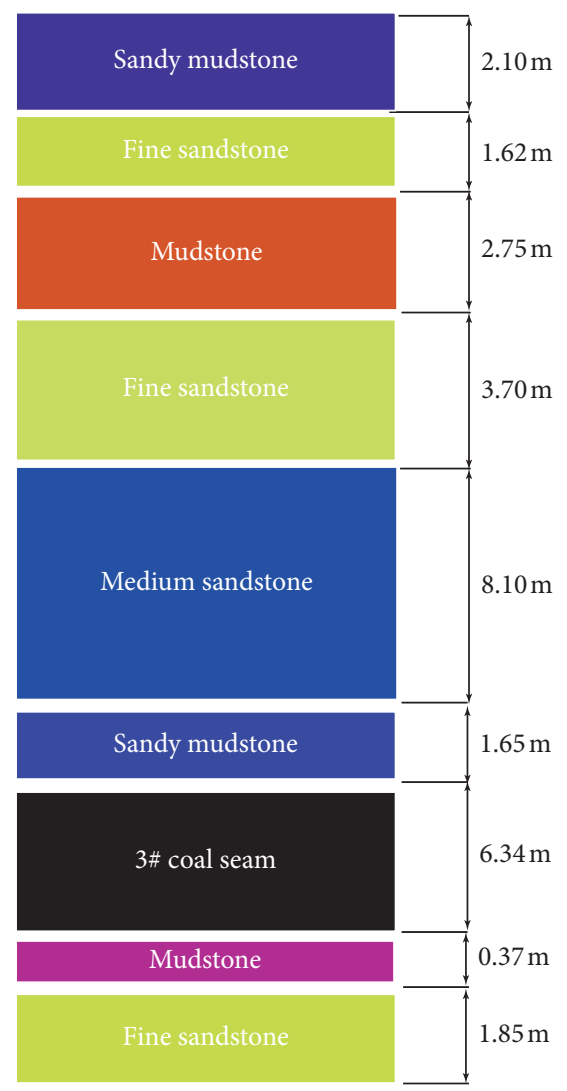

FIgURE 3: Lithology of the N1202 longwall.

TABLE 1: Key test results of rock samples.

\begin{tabular}{lccccc}
\hline Rock samples & UCS $(\mathrm{MPa})$ & Tensile strength $(\mathrm{MPa})$ & Elastic modulus $(\mathrm{GPa})$ & Poisson's ratio & Friction angle \\
\hline Fine sandstone & 95.0 & 9.5 & 35.1 & 0.2 & 30.0 \\
Medium sandstone & 72.0 & 7.5 & 25.0 & 0.2 & 31.0 \\
Sandy mudstone & 55.0 & 2.5 & 14.0 & 0.2 & 34.0 \\
3\# coal seam & 14.5 & 2.0 & 4.3 & 0.4 & 31.0 \\
Mudstone & 30.0 & 2.2 & 12.2 & 0.2 & 29.0 \\
\hline
\end{tabular}

Apart from the crushed zone, there is a fractured zone, mainly generated attributed to the stress wave rather than the shock wave. If the maximum tensile stress obtained from the stress wave is larger than the tensile strength of the surrounding rock, the fractured zone featured with huge shear/tensile cracks will be then generated. The radius of the fractured zone (i.e., $R_{2}$ ) is closely related to the tensile strength of surrounding rock. With the combination of the crushed zone and the fractured zone, the integrity of the hard overlying strata will be somehow changed and the potential risks of dynamic accidents will be correspondingly prevented.

It has been well noted that the detonation shock wave will directly act on the surrounding rock around the blast borehole through the air medium associated with the reflection and transmission of the shock wave. During the propagation process, the shock wave gradually propagates and both the crushing zone and fissure zone will be formed. In this research, the following four critical parameters (e.g., the radial noncoupling coefficient, blasting borehole spacing, group spacing, and the splitting width) were selected to investigate the effects of the presplit blasting technique.

3.1. Determination of Input Parameters. In this research, the input parameters were determined based on the geological and mining condition mentioned above. In accordance with the manual of LS-DYNA programme, the SOLID164 module was selected to generate the base model through the Euler grid. Differently, the ALE algorithm is used to establish the cartridge element. The air medium and the surrounding rock were obtained by the Lagrange algorithm. In building the numerical model, the blasting borehole was sealed with the 75-millimeterdiameter stemming. Considering the main strata above the coal seam to be the 8100-millimeter-thickness sandstone, they are selected to be the basic strata for the parametric studies presented in the following sections. Correspondingly, the mechanical properties of sandstone listed in Table 1 were adopted for numerical simulation. 


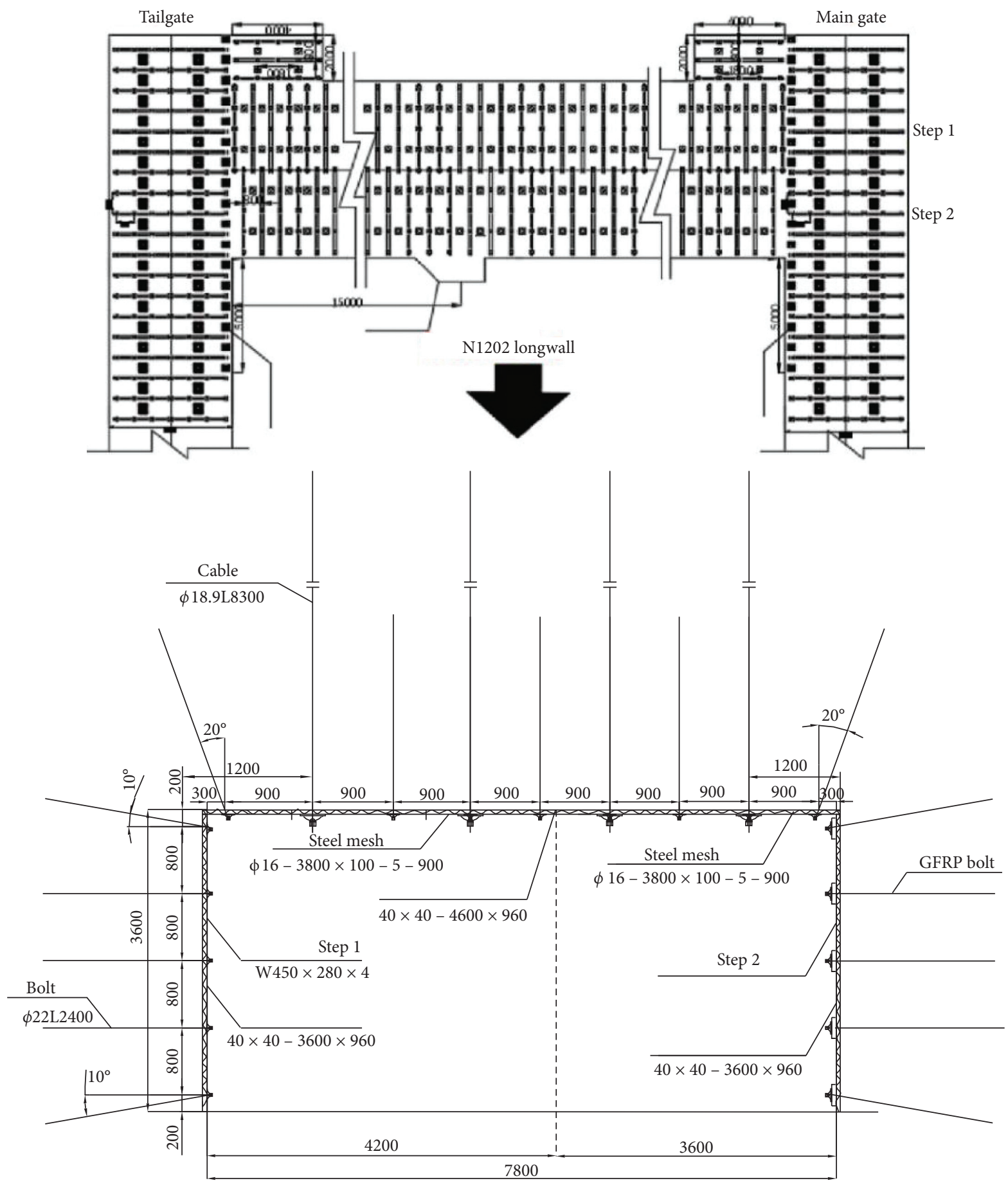

FIgURE 4: The cross section of the supported predriving roadway in the N1202 longwall.

The MAT-HIGH-EXPLOSIVE-BURN module was adopted to rebuild the cartridge element. The following equation represents the relationship between the shock stress $(P)$ applied to the surrounding rock and the relative volume $(V)[24]$ :

$$
P=A 1-\frac{\omega}{R_{1} V} e^{-R_{1} V}+B\left(1-\frac{\omega}{R_{2} V}\right) e^{-R_{2} V}+\frac{\omega E_{0}}{V},
$$

in which $A=78.1 \mathrm{GPa}, B=0.552 \mathrm{GPa}, R_{1}=4.02, R_{2}=0.91$, $\omega=1.4$, and $E_{0}=51 \mathrm{GPa}$.

The inherent element of "NULL" is adopted to generate the air element when the uncoupling blasting is considered.

$$
P=c_{0}+c_{1} \mu+c_{2} \mu+c_{3} \mu+\left(c_{4}+c_{5} \mu+c_{6} \mu\right) E_{0},
$$

in which $c_{0}=0.1, c_{1}=c_{2}=c_{3}=c_{6}=0, c_{4}=c_{5}=0.4$, and $E_{0}=250 \mathrm{~kJ}$. 


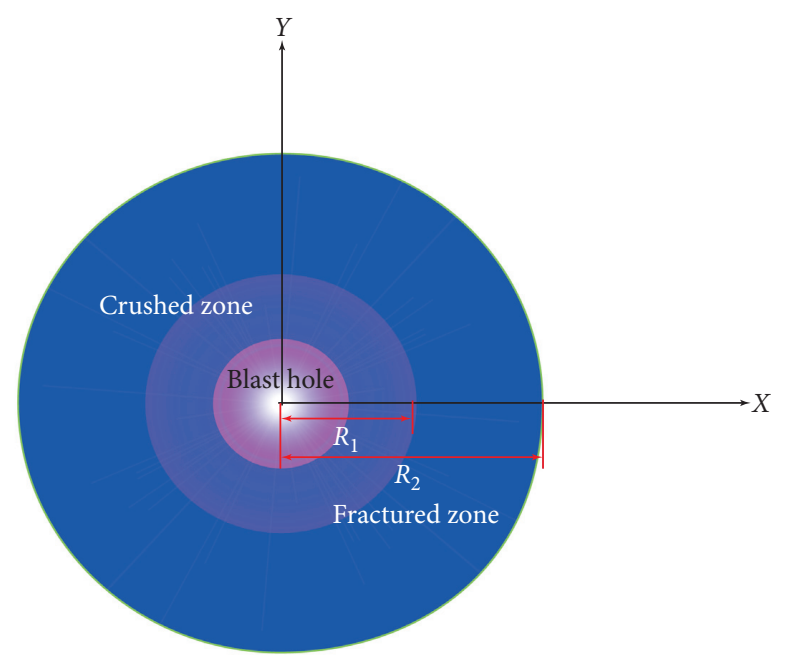

Figure 5: Classification of the crushed and fractured zones around the blast borehole.

The stemming was used to plug the blast borehole in the N1202 working face of Yuwu coal mine, which is simulated by the inherent MAT-SOIL-AND-FOAM element. With the consideration of conventional experience in underground blasting, the 4000-millimeter-length stemming is used in this research.

3.2. Effect of Noncoupling Coefficient. The value of the noncoupling coefficient is generally smaller than 2 , and thus the following values $(1.15,1.25,1.5$, and 1.75) were adopted to investigate the effect of the noncoupling coefficient on the behaviour of the damaged surrounding rock. To obtain an in-depth understanding of the transmission of the shock wave and determine the radius of the crushed zone and fractured zone, the centre point of the blasting borehole is fixed as the reference point and the other five monitoring points apart from the reference point are nonuniformly distributed in accordance with the layout shown in Figure 6.

When the noncoupling coefficient is equal to 1 , the distribution of the von Mises stress at different processes is presented in Figure 7. It is apparent that the shock wave decreased with the time and the stress applied to the surrounding rock nearby the blasting borehole experiences consequently a decrease. As can be seen from Figure 7, the effect of shock wave applied to the surrounding rock is not obvious when $T=3.6 \mathrm{~ms}$. It is thus believed that the generation of the crushed and fractured zone is within $2.3 \mathrm{~ms}$.

Figure 8 presents the monitored shock wave pressure at different times, in which the pressure is simultaneously recorded by the programme itself. It is obvious that the peak pressure at point $A$ is larger than $320 \mathrm{MPa}$ corresponding to the time equal to $0.3 \mathrm{~ms}$, indicating that the crushed zone was generated within this time. From then on, the shock wave acted on the surrounding rock experiences a sharp decrease and the value of which tends to be zero when $T=2.3 \mathrm{~ms}$.
To enhance the effects of presplit blasting, it is suggested to increase the effective time of the stress wave and the transmission of blasting air rather than the shock wave. If so, the radius of the crushed zone will be decreased and the fractured zone will be enlarged. It can be seen in Figure 9 that the maximum stress at point $A$ is $320 \mathrm{MPa}$ and the peak strength monitored at point $B$ is $60 \mathrm{MPa}$ at $0.4 \mathrm{~ms}$. With the consideration of the mechanical properties of the surrounding rock listed in Table 1, it is supposed that the radiuses of the crushed zone and fractured zone are $1 \mathrm{~m}$ and $3.5 \mathrm{~m}$, respectively. The generation of these fractured zones is within 2.3-4.0 ms, which is not good enough in respect of increasing the diameter of the fractured zone.

In the following section, the effects of noncoupling coefficient are investigated through the comparison of the numerical results. In these cases, the shock wave will be directly applied to the air layer, which is used to separate the cartridge rolls, rather than the surrounding rock. Because the air layer will absorb somewhat energy, the radius of the crushing zone will be correspondingly reduced and the effected zone of the fractured zone will be therefore increased, which can be seen in Figure 10.

Figure 11 presents the effective stress obtained from different monitoring points with different $K$ values. When the value of $K$ is equal to 1.15 , the peak stresses obtained from different monitoring points (e.g., $A, B$, and $C$ ) are $140 \mathrm{MPa}$ at $0.43 \mathrm{~ms}, 64 \mathrm{MPa}$ at $0.9 \mathrm{~ms}$, and $29 \mathrm{MPa}$ at $1.9 \mathrm{~ms}$. When it is compared with the coupling coefficient $(K=1)$, the reach of the shock wave on the surrounding rock has been significantly postponed. It can also be found that the stress obtained from point $A$ experiences a decline, whereas the monitored stress at pint $C$ is larger than that when $K=1$, indicating that the energy dissipation of the shock wave in the crushing zone is significantly reduced. As a result, much more energy will be used to increase the crack expansion, resulting in the increase of the radius of the fractured zone.

Given the dynamic compressive strength of surrounding rock listed in Table 1, the estimated diameter of the crushed zone is still smaller than $1 \mathrm{~m}$, suggesting that the effect on the crushed zone is not obviously affected when the nondecomposition coefficient increased to 1.15 . With the consideration of the monitored tensile stresses are $9 \mathrm{MPa}$ at point $C$ and $10 \mathrm{MPa}$ at point $D$, the radius of the fractured zone is estimated to be around 3.5-4 m. The other notable observation is that the action time of the shock wave on surrounding rock is among 3-6 ms, which is much larger than that when $K=1$.

It can be seen from Figure 11 that there is still a very high effective strength nearby the blasting borehole when $K=1.25$. The positive pressure action time for the formation of the fractured zone is much longer in this case. Correspondingly, the minor cracks are further expanded and the radius of the fractured zone is enlarged. With the increase of the $K$ value, the stress wave attenuates greatly at $3.5 \mathrm{~ms}$. It can also be found that the effective stresses with the $K$ value of 1.5 at different monitoring points are obviously smaller than their counterparts with the $K$ value of 1.15 and 1.25, respectively. 


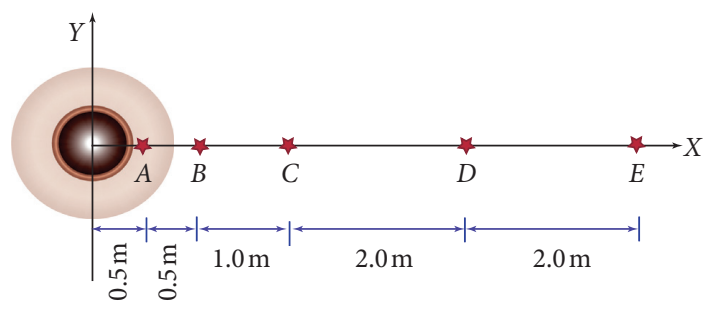

FIGURE 6: The schematic of monitoring points apart from the centre of the blast borehole.

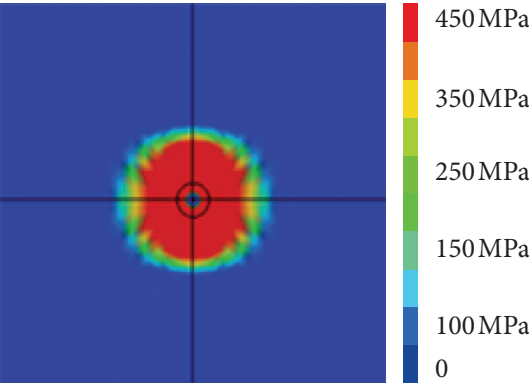

(a)

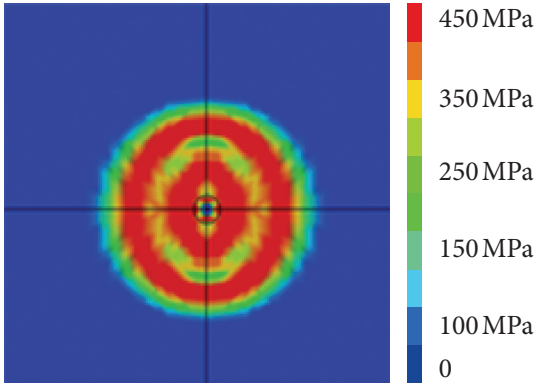

(b)

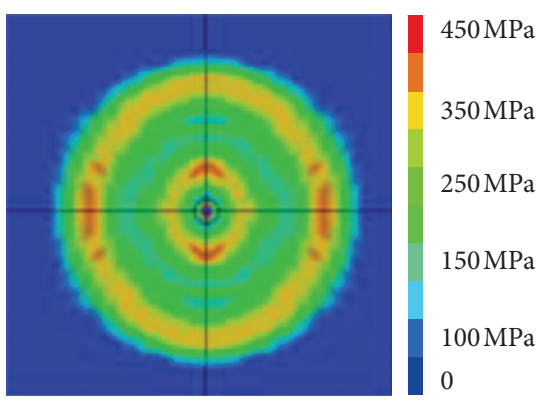

(c)

FIgURE 7: The evolution of the effective stress in the surrounding rock at different times. (a) $T=1.1 \mathrm{~ms}$. (b) $T=2.3 \mathrm{~ms}$. (c) $T=3.6 \mathrm{~ms}$.

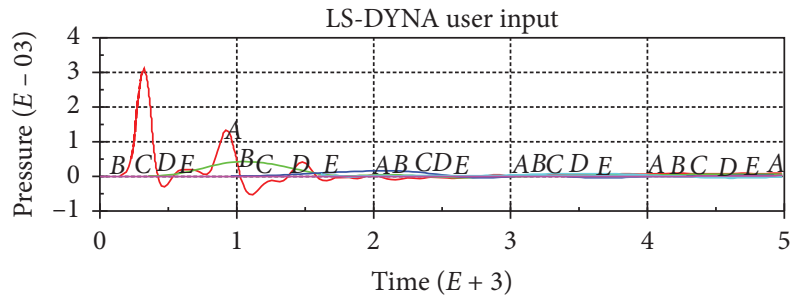

Element no.

\begin{tabular}{llll}
$\frac{A}{B}$ & 5551 & $\frac{D}{E}$ & 630 \\
\hline$C$ & 675 & - & 590 \\
\hline & 660 & &
\end{tabular}

Figure 8: The effective stress obtained from different monitoring points.

When the value of $K$ increases to 1.5 , the peak stress at point $A$ is $93.5 \mathrm{MPa}$ at $0.45 \mathrm{~ms}$, which is larger than that of the peak strength of surrounding rock. The monitored peak stress at point $B$ is $46.5 \mathrm{MPa}$ when $T=0.9 \mathrm{~ms}$, the value of which is larger than that of the mudstone and sandy mudstone. Even though, this stress is not enough to crush the sandstone and can only generate somewhat fractures and cracks. The declined peak stresses at points $A$ and $B$ are the direct evidence to support the assumption that the shock wave mainly works on the fractured zone with the increased radius. When the tensile stresses obtained from points $C$ and $D$ are all higher when they are compared with their counterparts with smaller $K$ values, the increased tensile stress is actually suitable to generate much more cracks around the blasting borehole. As depicted in Figure 10, the radius of the
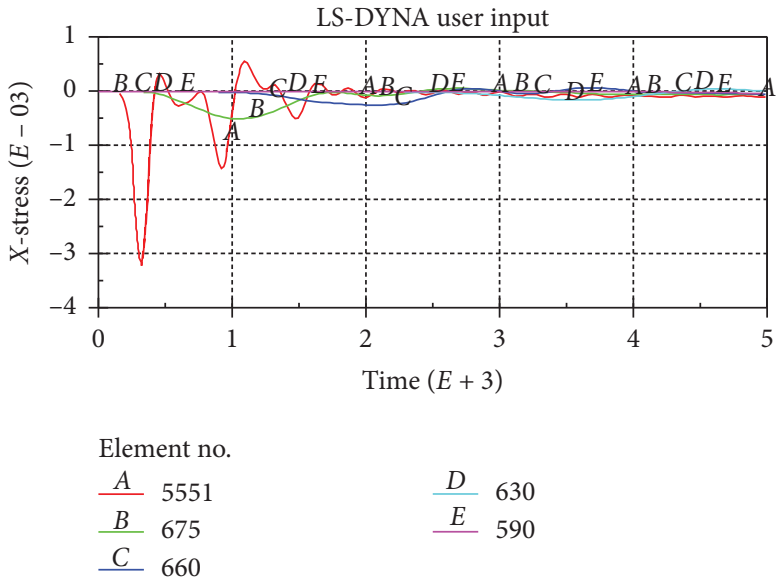

Figure 9: The stress-time curve for radial coupled charge.

fractured zone is beyond $3.5 \mathrm{~m}$, which is larger than that with other $K$ values.

With the continuous increase of the $K$ value, much more cracks and fractures may be generated. As illustrated in Figures 10-11, the radius of the crushed zone is too small when $K=1.75$. In this case, the limited numbers of initial cracks around the crushed zone cannot guarantee the requested distribution of the fractured zone. Although the shock wave and the explosion gas will work together to expand these cracks, they can only increase the length of these separated cracks, mainly attributed to the generated crushed zone with smaller radius (i.e., $0.4 \mathrm{~m}$ ). According to the above analysis and discussions, the optimised $K$ value is 


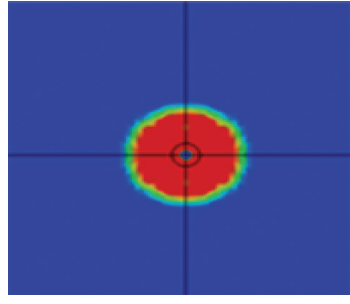

(A) $T=1.2 \mathrm{~ms}$

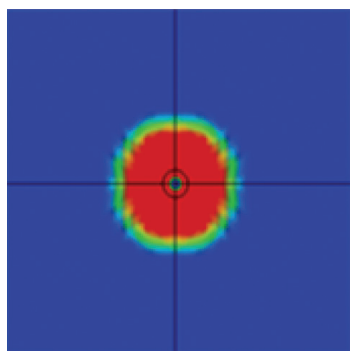

(A) $T=1.3 \mathrm{~ms}$

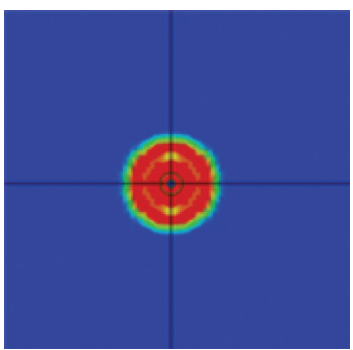

(A) $T=1.2 \mathrm{~ms}$

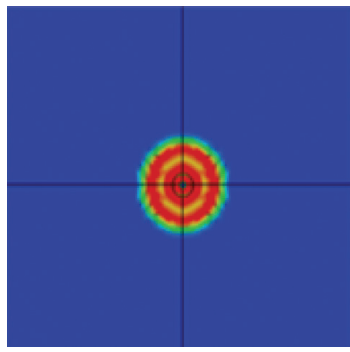

(A) $T=1.2 \mathrm{~ms}$

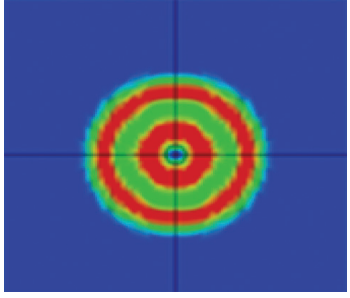

(B) $T=2.5 \mathrm{~ms}$

(a)

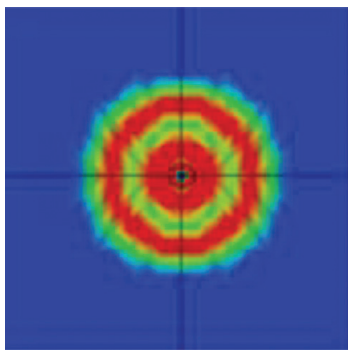

(B) $T=2.3 \mathrm{~ms}$

(b)

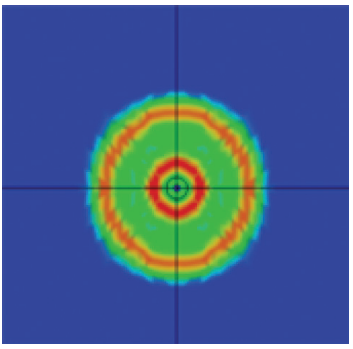

(B) $T=2.5 \mathrm{~ms}$

(c)

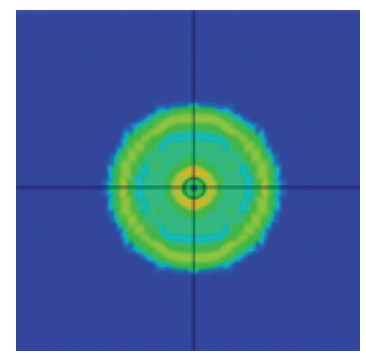

(B) $T=2.3 \mathrm{~ms}$

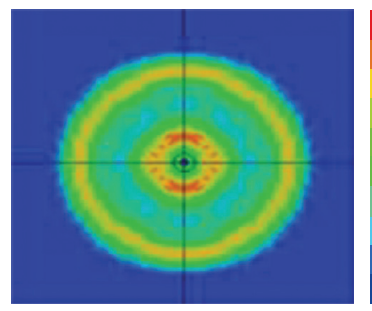

$350 \mathrm{MPa}$

$300 \mathrm{MPa}$

$250 \mathrm{MPa}$

$200 \mathrm{MPa}$

$150 \mathrm{MPa}$

(C) $T=3.6 \mathrm{~ms}$

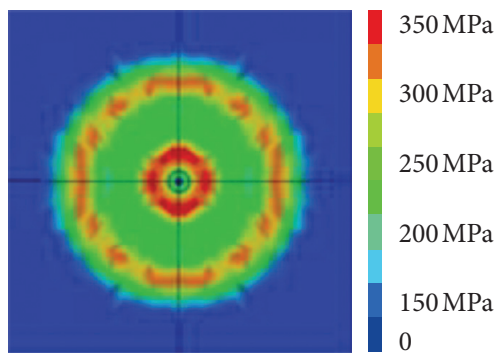

(C) $T=3.4 \mathrm{~ms}$

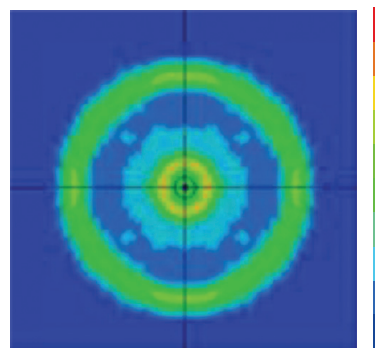

$350 \mathrm{MPa}$

$300 \mathrm{MPa}$

$250 \mathrm{MPa}$

$200 \mathrm{MPa}$

$150 \mathrm{MPa}$

(C) $T=3.5 \mathrm{~ms}$

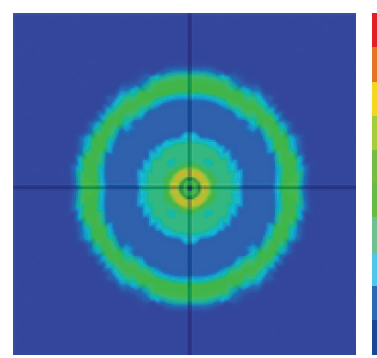

$350 \mathrm{MPa}$

$300 \mathrm{MPa}$

$250 \mathrm{MPa}$

$200 \mathrm{MPa}$

$150 \mathrm{MPa}$

(C) $T=3.4 \mathrm{~ms}$

(d)

Figure 10: The evolution of the effective stress in the surrounding rock at different times. (a) $K=1.15$. (b) $K=1.25$. (c) $K=1.5$. (d) $K=1.75$.

1.5 from the numerical simulation with the simple assumption as stated earlier.

3.3. The Effect of the Borehole Spacing in the Same Group. The above analysis of the single blasting borehole can help to deepen the understanding of the presplit blasting technique. However, the blast boreholes are either generally detonated in the group or some multiple blast boreholes are detonated together in practical applications. In this section, it is simply assumed that there are three blasting boreholes in the same group; the numerical simulation was thus conducted to investigate the effect of different borehole spacing. With the consideration of the geological and mining conditions mentioned earlier, three typical borehole spacing values (e.g., $3 \mathrm{~m}, 6 \mathrm{~m}$, and $9 \mathrm{~m}$ ) were inputted. Different monitoring points were set up along the $X$ - and $Y$-axes with the central point in the middle of the blasting borehole as illustrated in Figure 12.

It is expected to obtain the proper blasting borehole spacing based on the systematic of the monitored stresses from two different axes and the stress distribution 


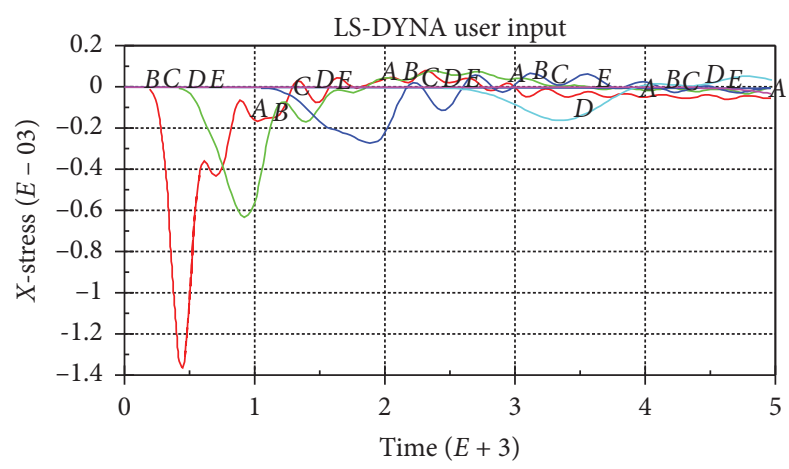

Element no.

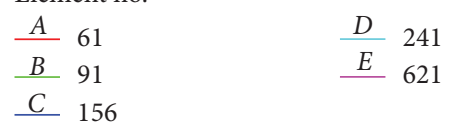

(a)

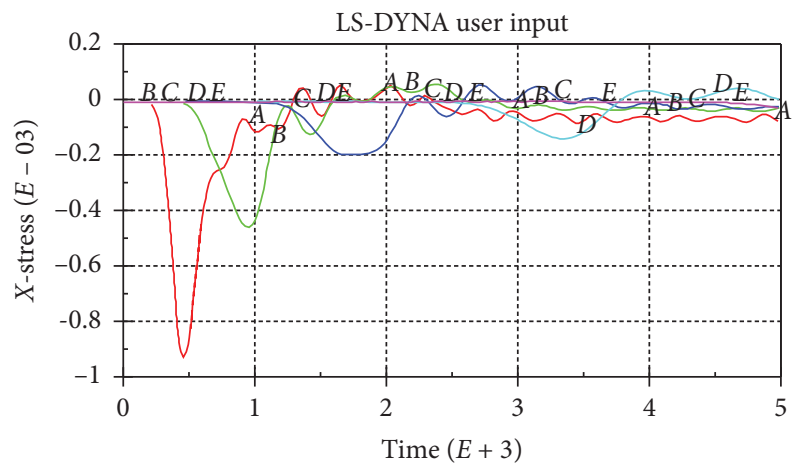

Element no.

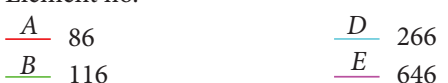

$\begin{array}{ll}C & 181\end{array}$

(c)

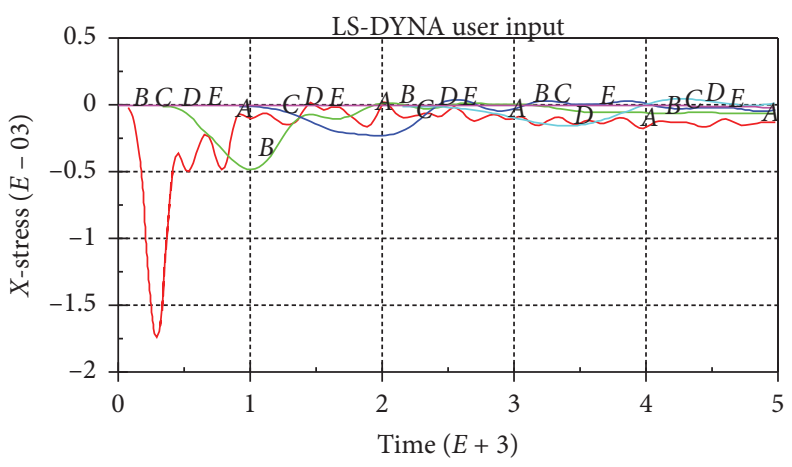

Element no.

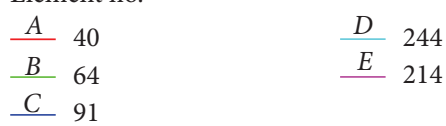

(b)

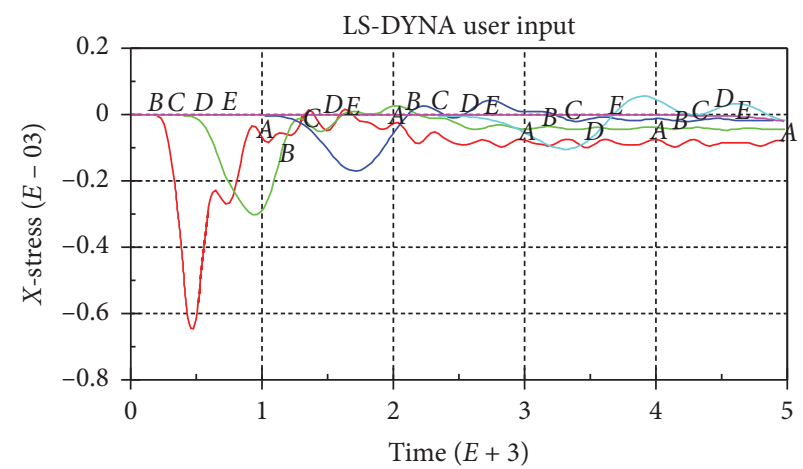

Element no.

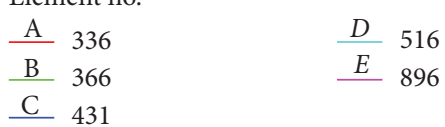

(d)

Figure 11: The effective stress obtained from different monitoring points with different $K$ values. (a) $K=1.15$. (b) $K=1.25$. (c) $K=1.5$. (d) $K=1.75$.

characteristics. According to the monitoring results in two directions as shown in Figure 13, the occurrence of the stress increase will take place in some areas due to the superimposition of stress waves in the process of propagating in the rock formation. At these superimposition areas, the surrounding rock will be crushed and the radius of the fractured zone will be a little bit smaller.

Figures 14 and 15 present the effective pressure recorded at different monitoring points from different axis, respectively. When the value of the borehole spacing ranges from $3 \mathrm{~m}$ to $8 \mathrm{~m}$, the radius of the signal fractured zone is $4 \mathrm{~m}$ and the sum radius of the crushed zone is $3 \mathrm{~m}$, which can ensure the formation of the expected fractured zone between two blast boreholes in the same group. The suitable spacing between each borehole should be therefore in the range of 3-8 $\mathrm{m}$. However, with the increase of the spacing between two blast boreholes, namely, $L>8 \mathrm{~m}$, it becomes difficult to obtain enough cracks and fractures and the distance between each blast borehole should be within 3-6 m.
3.4. The Effect of the Borehole Spacing in Different Groups. In practice, the blasting boreholes are drilled in rows and the fractures attributed to the blasting may be connected. In this section, the effects of the space between different blasting boreholes are investigated. In accordance with the geological and mining conditions, two typical spaces $\left(L_{1}=6 \mathrm{~m}\right.$ and $L_{2}=8 \mathrm{~m}$ ) were selected and compared. To evaluate the effect of the borehole spacing, six points were marked to record the maximum stress. More detailed information about the layout of the monitoring points can be found in Figure 16.

Figure 17 presents the monitored stress distributed around the $Y$-direction with different borehole spacing and Figures 18-19 present the distribution of the stress around the blasting boreholes. According to the results presented above, the peak tensile stress intensity of each tracking unit is weaker than when the group space is $6 \mathrm{~m}$, and the peak intensity time is also delayed. If the group space is equal to $6 \mathrm{~m}$, the peak compressive stresses obtained from points $A$, $B$, and $C$ are $16 \mathrm{MPa}$ at $2.6 \mathrm{~ms}, 17 \mathrm{MPa}$ at $2.7 \mathrm{~ms}$, and $19 \mathrm{MPa}$ 


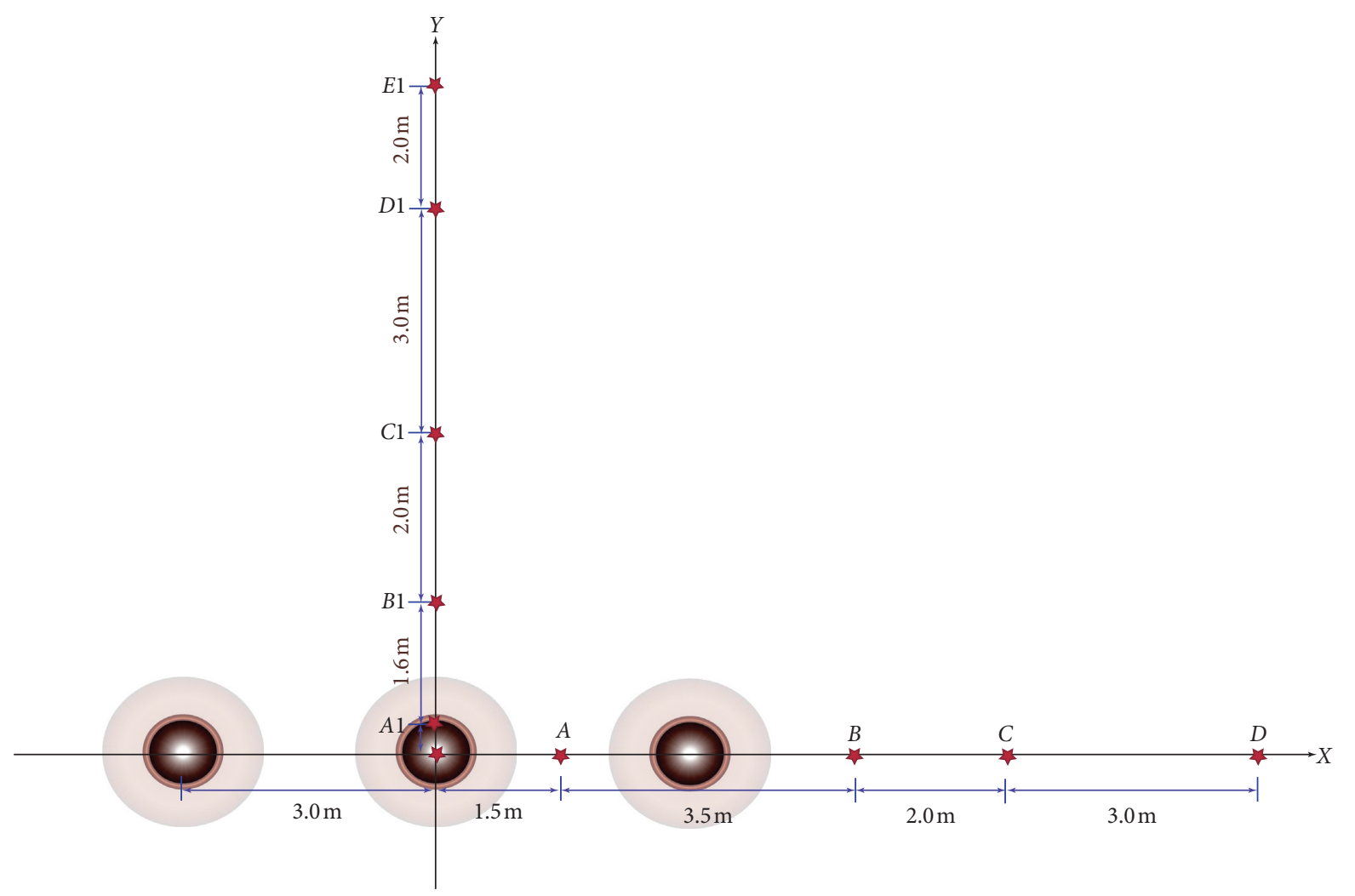

FIGURE 12: Layout of monitoring points.

at $3.5 \mathrm{~ms}$, respectively. The cross section of the crushed zone along the $Y$-direction is about $4 \mathrm{~m}$, which can cover the width of the working face. When the borehole spacing increased to $8 \mathrm{~m}$, the crack expansion radius is between 2 and $4 \mathrm{~m}$, which is significantly lower than that with a group spacing of $6 \mathrm{~m}$.

It can be comprehensively known that in the actual engineering design, the blast borehole groups at both ends of the working face, the group spacing is generally designed to be within $8 \mathrm{~m}$, which can better ensure that there are partial penetration cracks at the end position, and the partial penetration cracks will continue to extend and expand in the later stage, so as to realize the cutting of the entire working face roof along the cutting hole position of the working face to ensure the presplitting effect.

3.5. The Effect of the Split Width. The split width is the other critical parameter to be considered in practice. If the split width is too large, the energy cannot be concentrated which will not obtain an effective explosive. If the split width is too small, it will be very difficult to get the expected fractures. Therefore, in this section, the 15-millimeter-width split was adopted to investigate the effect of split width with the comparison between the normal cartridge pack. The dimeter of the blasting hole is $64 \mathrm{~mm}$, which is in accordance with the PVC tube used in practice.

Different from the stress distribution of normal cartridge pack shown in Figure 20, it is apparent that the energy from the shock wave is concentrated around the split. In particular, the stresses applied to the surrounding rock are much larger when $T=1 \mathrm{~ms}$ and $T=1.5 \mathrm{~ms}$. The main reason for this difference is that the shock wave will firstly be applied to the surrounding rock nearby the split line which acts as a pilot line. The shock wave will be generally transferred along the split line and then make the shock wave (stress wave) and explosive gas penetrate the initial crack along the direction of the incision. Then, the cracks will be further expanded and penetrated along the line of the blast borehole. Compared with the normal cartridge pack, the existing of the split reduces the excessive dissipation of explosion energy in other directions and thus improves the effect of presplit blasting effects.

Five monitoring points apart from the central point with various distance $(0.5 \mathrm{~m}, 1 \mathrm{~m}, 2 \mathrm{~m}, 4 \mathrm{~m}$, and $6 \mathrm{~m})$ were set up to track the peak stress of the shock wave, the results of which are presented in Figures 21 and 22. It is obvious that the peak stress at point $A$ is about $170 \mathrm{MPa}$ at $0.3 \mathrm{~ms}$ if there is a split, whereas the peak value of the detonation wave pressure at point $A$ is only $130 \mathrm{MPa}$ corresponding to the time of $0.4 \mathrm{~ms}$. With the consideration of the distance between point $A$ and the split line, it is believed that the detonation wave pressure around the split is much greater than that where there is no split, indicating that the existence of the split is obvious. However, the pressure at points $B, C$, and $D$ apart from the split line are slightly smaller than that if there is no split constructed. This observation is mainly attributed to the wave reflection associated with the energy loss. As a result, the radius of the crushed zone is smaller than that without the split. The slit-guided high-energy jet 


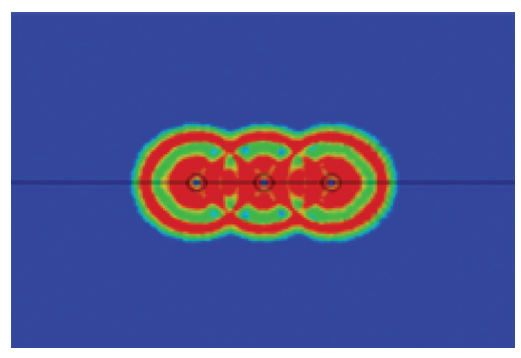

(A) $T=2.0 \mathrm{~ms}$

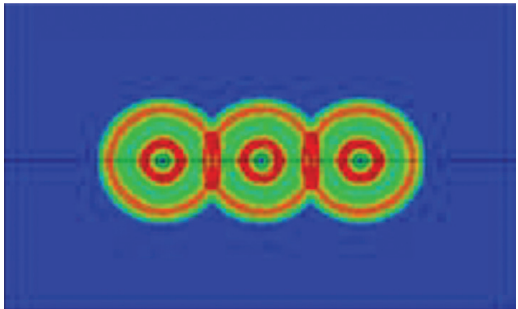

(A) $T=2.8 \mathrm{~ms}$

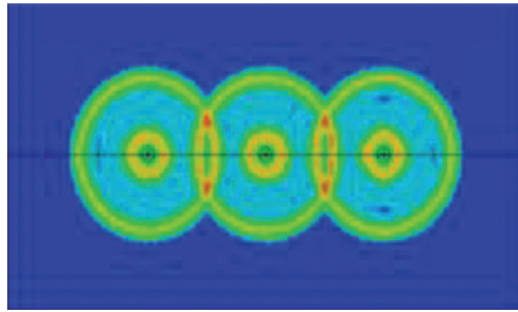

(A) $T=3.8 \mathrm{~ms}$

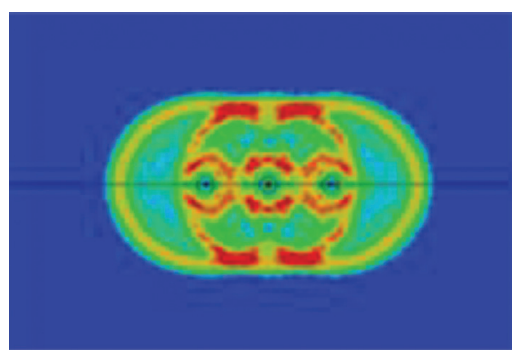

(B) $T=3.5 \mathrm{~ms}$

(a)

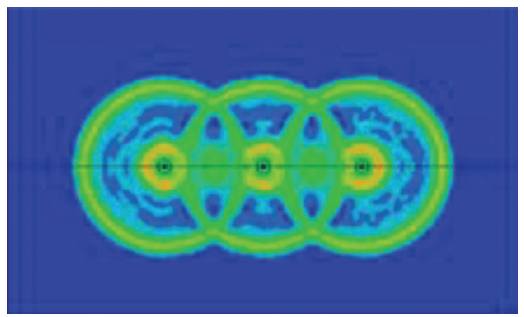

(B) $T=4.0 \mathrm{~ms}$

(b)

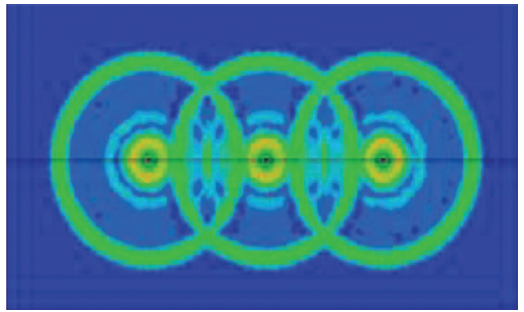

(B) $T=4.9 \mathrm{~ms}$

(c)

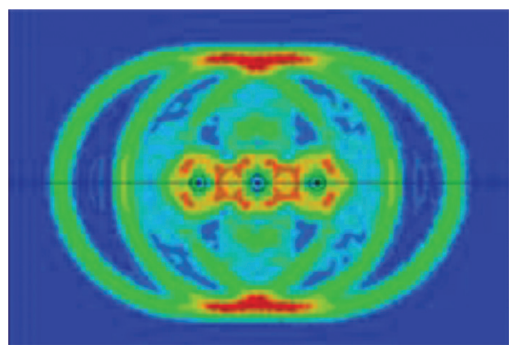

(C) $T=5.5 \mathrm{~ms}$

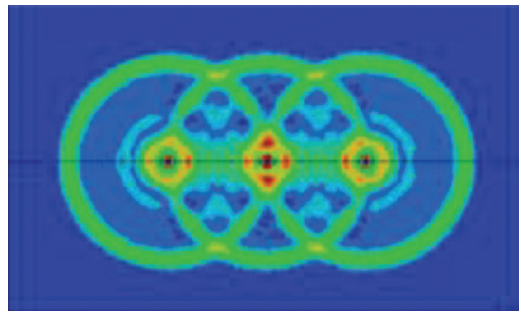

(C) $T=4.8 \mathrm{~ms}$

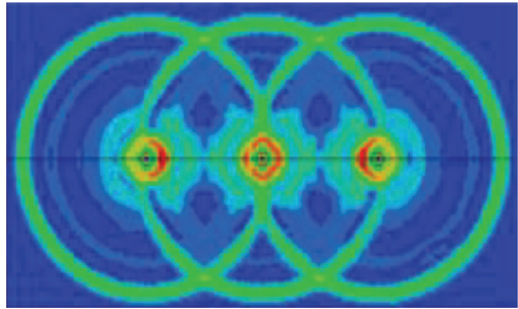

(C) $T=6.7 \mathrm{~ms}$

FIGURE 13: Distribution of stress with different blasting borehole spacing from the same group. (a) $L=3.0 \mathrm{~m}$. (b) $L=6.0 \mathrm{~m}$ (c) $L=8.0 \mathrm{~m}$.

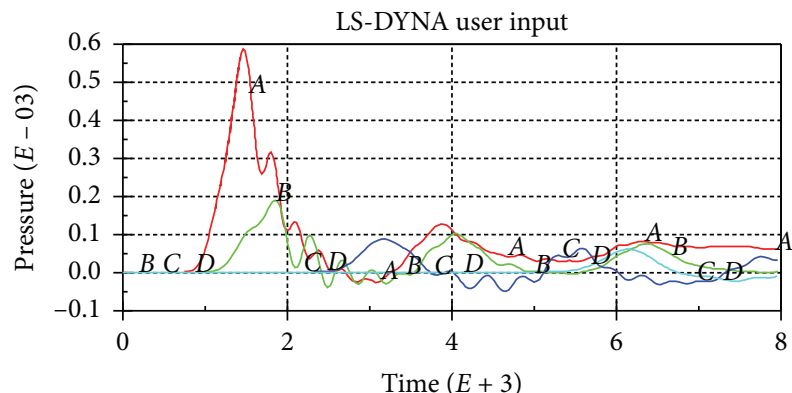

Element no.

$\frac{A}{B} 2141$

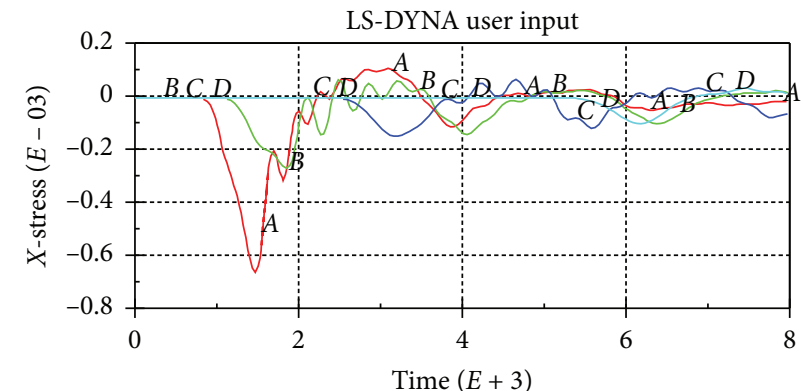

Element no.

$\begin{array}{ll}A & 2141 \\ B & 2321\end{array}$

\begin{tabular}{lr}
$C$ & 2391 \\
\hline$D$ & 2531
\end{tabular}

(a)

$\begin{array}{ll}C & 2391 \\ & 2531\end{array}$ (b)

Figure 14: Continued. 


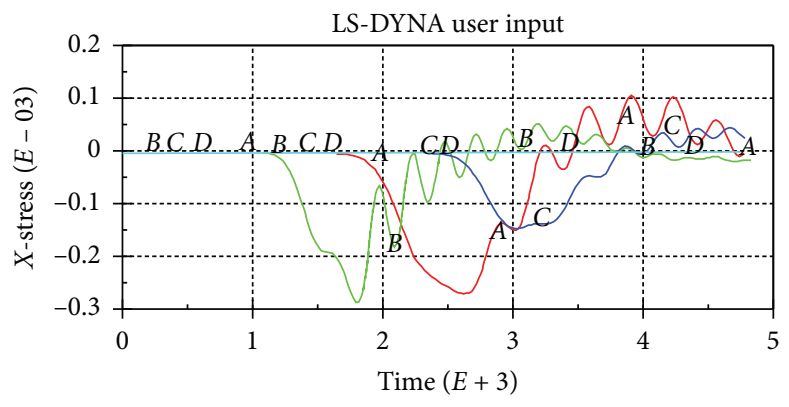

Element no.

$$
\begin{array}{llll}
\frac{A}{B} & 4365 & \frac{C}{D} & 3785 \\
\underline{B} & 3685 & & 4000
\end{array}
$$

(c)

Figure 14: Stress at the $X$-axis in the blasting borehole with different values of $L$ (a) $L=3 \mathrm{~m}$. (b) $L=6 \mathrm{~m}$. (c) $L=8 \mathrm{~m}$.

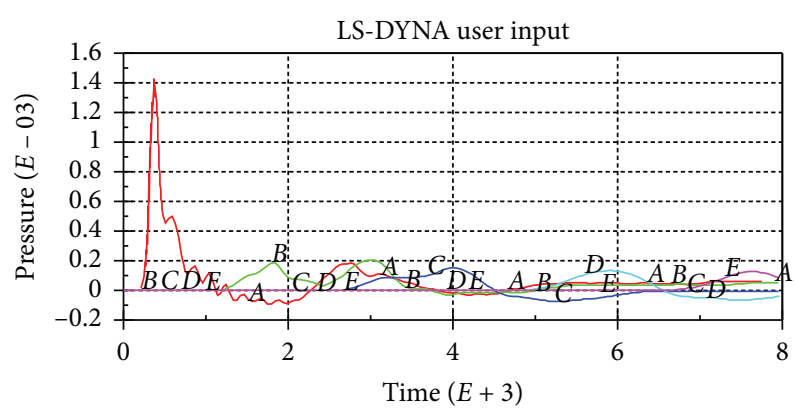

Element no.

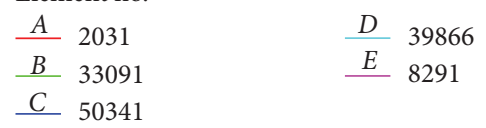

(a)

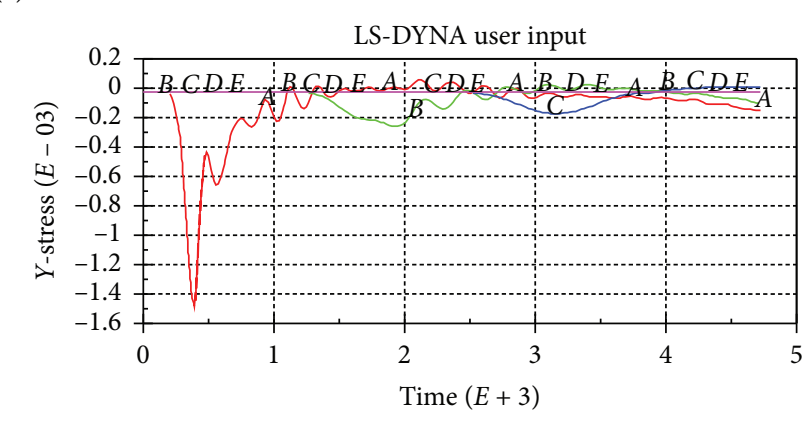

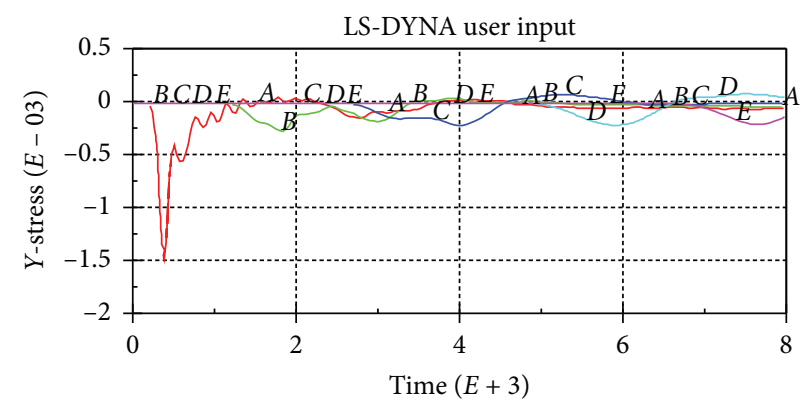

Element no.
A 2031
D 39866
B 33091
E 8291

(b)

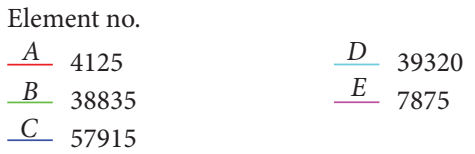

(c)

Figure 15: Stress at the $Y$-axis in the blasting borehole with different values of $L$ (a) $L=3 \mathrm{~m}$. (b) $L=6 \mathrm{~m}$. (c) $L=8 \mathrm{~m}$.

and explosive gas diffuse to both sides along the slit to further increase the residence time of the two in the initial fissure. In this case, more energy will work on the expansion of the blast fissure. In general, the radius of the fissure zone is larger than that of the latter, which is conducive to the formation of through fissures along the central line of the 


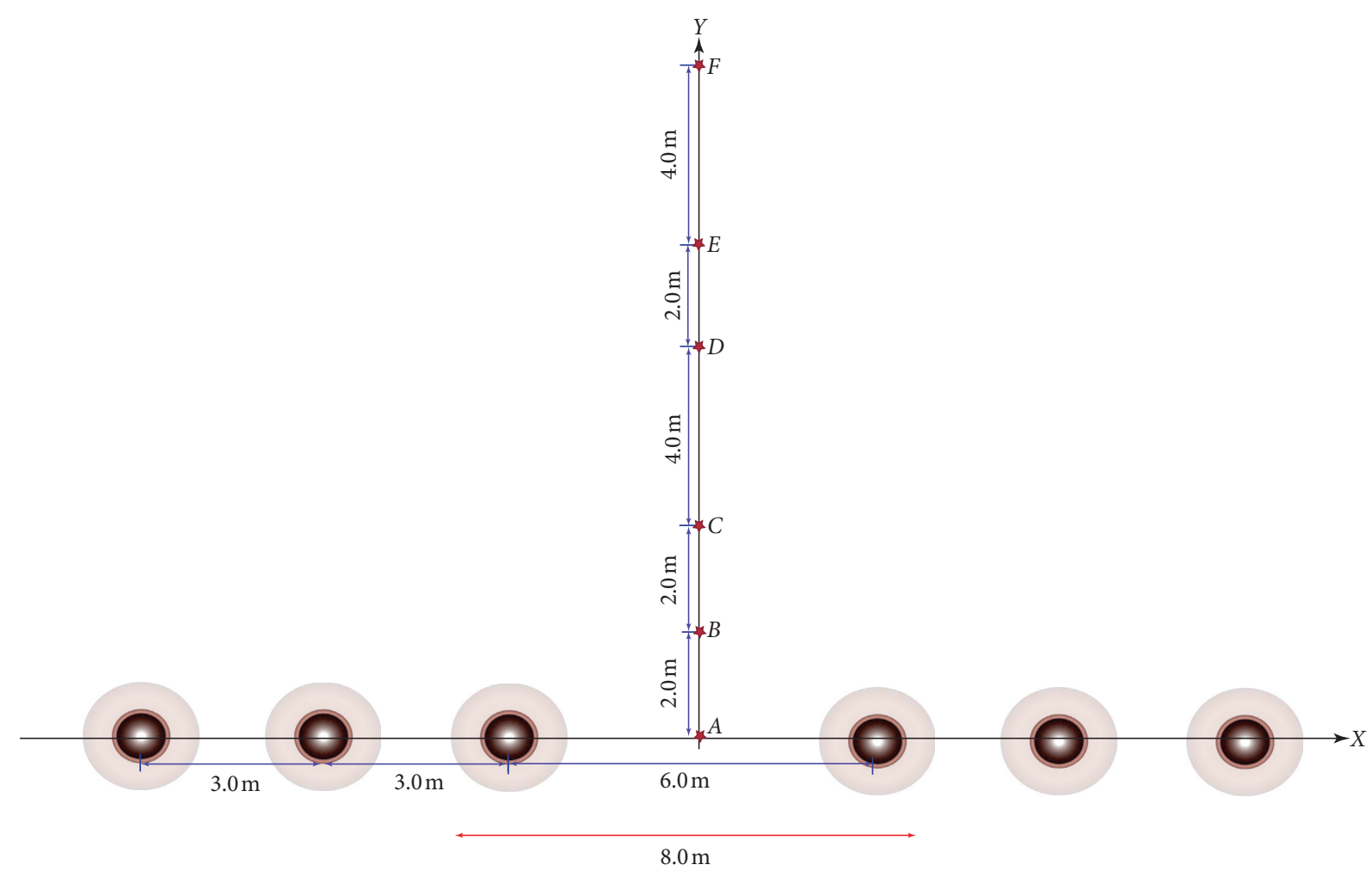

FIGURE 16: Layout of monitoring points.

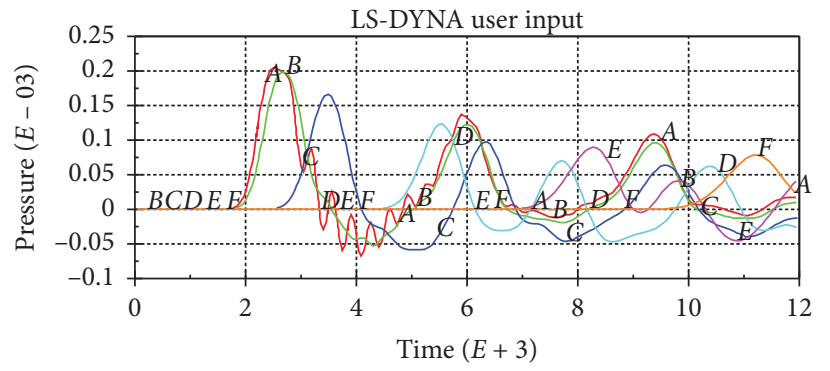

Element no.

$\begin{array}{ll}\frac{A}{B} & 4201 \\ & 29731 \\ C & 73141\end{array}$

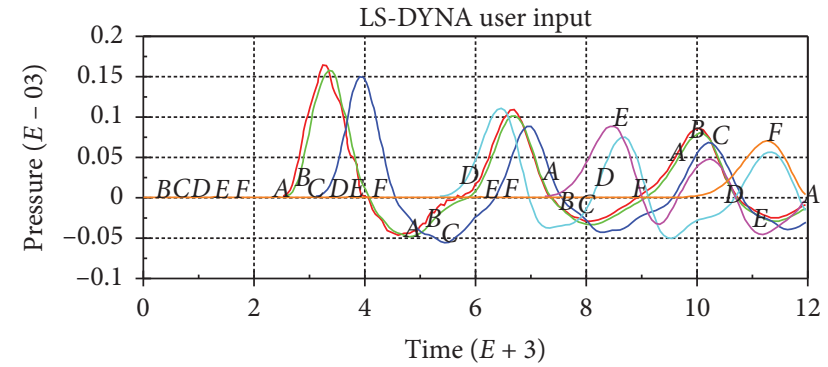

Element no.

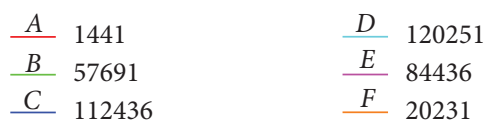

(b)

Figure 17: The effective stress obtained from different monitoring points with different spacing. (a) $L=6 \mathrm{~m}$. (b) $L=8 \mathrm{~m}$.

blast borehole to achieve the purpose of precracking the roof. According to above discussion, the 15-millimeterwidth split is recommended.

\section{Field Study}

4.1. Overview. The layout of the blasting borehole to pretreat the hard roof of the longwall N1202 can be seen from Figure 23 , in which the number is used to clarify the location of the blasting borehole. A total of 49 blasting boreholes with the length of $15 \mathrm{~m}$ were drilled by the functions, among which two blasting boreholes were located at the conner of the main gate and the tailgate, respectively.

The critical parameters determined by the numerical simulation were adopted in this research to pretreat the hard roof. With the consideration of the existed fractures and cracks before the application of the presplit blasting technique, the radial noncoupling coefficient of 1.5 is applied. 

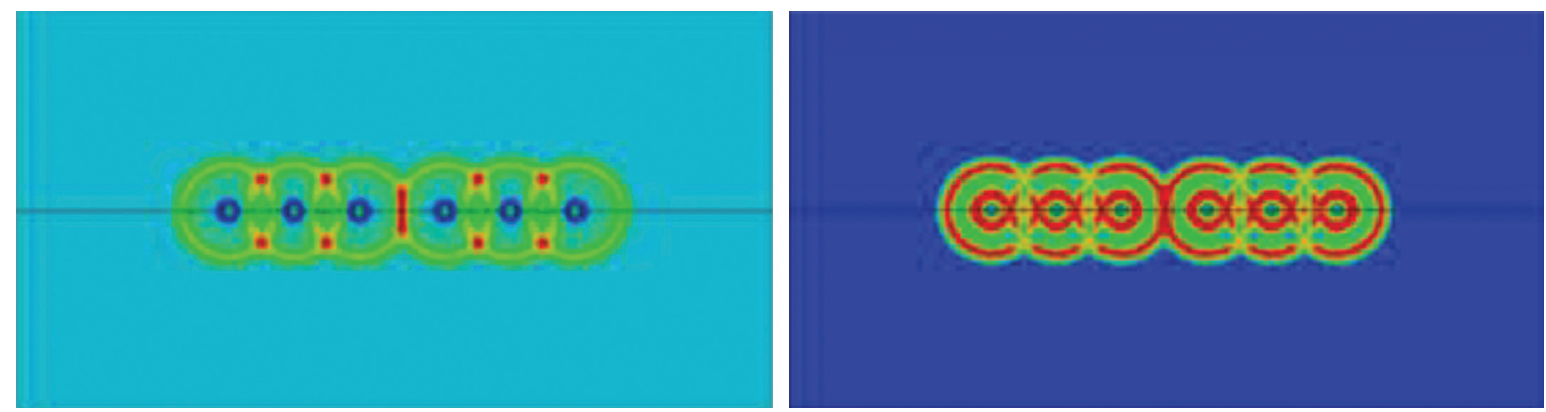

(a)
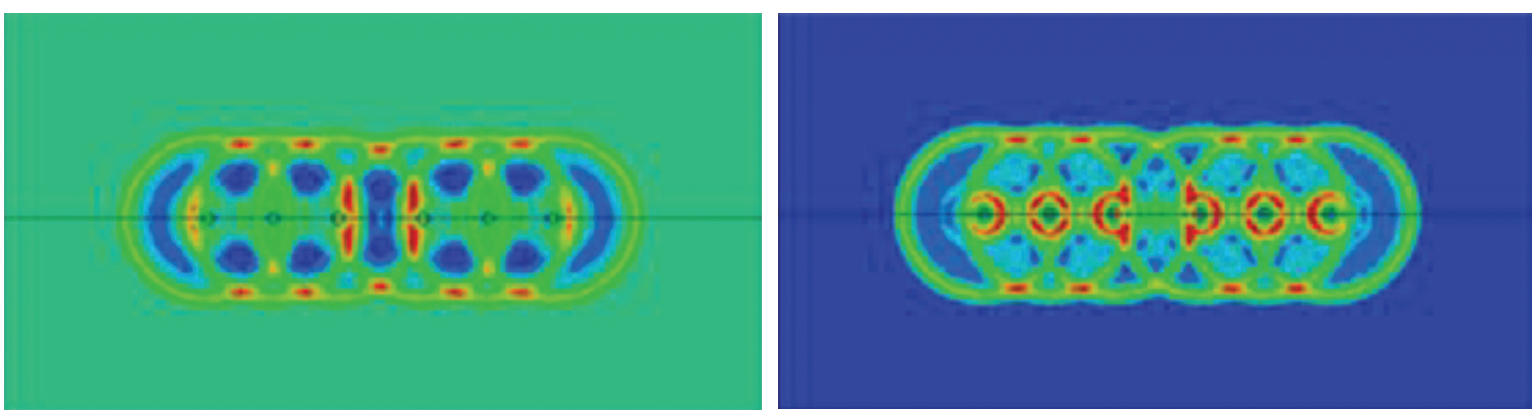

(b)
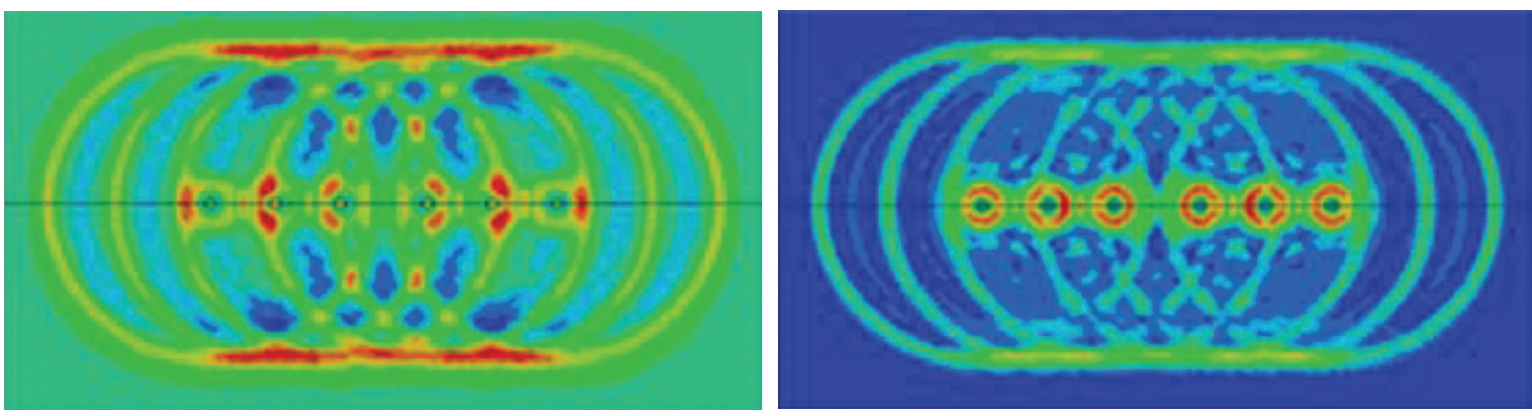

(c)

Figure 18: The evolution of the effective stress in the surrounding rock with the borehole spacing of $6 \mathrm{~m}$ at different times. (a) $T=2.7 \mathrm{~ms}$. (b) $T=4.6 \mathrm{~ms}$. (c) $T=8.6 \mathrm{~ms}$.

The borehole spacing in the same group and different groups are $5 \mathrm{~m}$ and $6 \mathrm{~m}$, respectively. The split width of $15 \mathrm{~mm}$ is used. In addition, two detonating cords and two detonators are designed to detonate the charge at the same time, which ensures that the charge can be detonated smoothly.

4.2. Evaluation of the Presplit Blasting Effects. To evaluate the effect of using presplit blasting technique in weakening the hard overlying strata, the breakage of the hard overlying strata and the inner structures of the surrounding rock nearby the blasting borehole were adopted in this research. The measured cracked length of the hard roof reduces to $18 \mathrm{~m}$, which is acceptable for coal operators. As observed from field investigation, there was still somewhat deformation, the evidence of which is that some blasting boreholes drilled among the 130\#-143\#, 173\#-3\# hydraulic chocks were sealed due to the collapse of the top coal seam. To maintain the stability of the overlying strata, the timber chocks were installed as shown in Figure 24.
Figure 25 presents the inner structures of the blasting boreholes at different depth, from which the effect of presplit blasting technique can be further examined. It is apparent that the surrounding rock nearby the blasting borehole is crushed within the depth of 2-5 m. Most importantly, there is obvious separation between the top coal and the sandy mudstone. Starting from $3.8 \mathrm{~m}$ to $4.8 \mathrm{~m}$, there are lots of fractures distributed along the blasting borehole. With the increase of the depth, the horizontal fractures were observed at the depth of 6-8 m, indicating the effective radius of the crushed zone is among this area. As expected, there is no crushed rock observed from the blasting borehole with the depth of 9-12 m. However, the horizontal fractures in these zones are much more obvious, which agrees well with the numerical modelling. As shown in Figure 25, the distribution of fractures is much more random and some surrounding rock experiences the crush. The main reason for this observation is probably attributed to the reflection of shock wave, which is located at the bottom of the blasting borehole. 

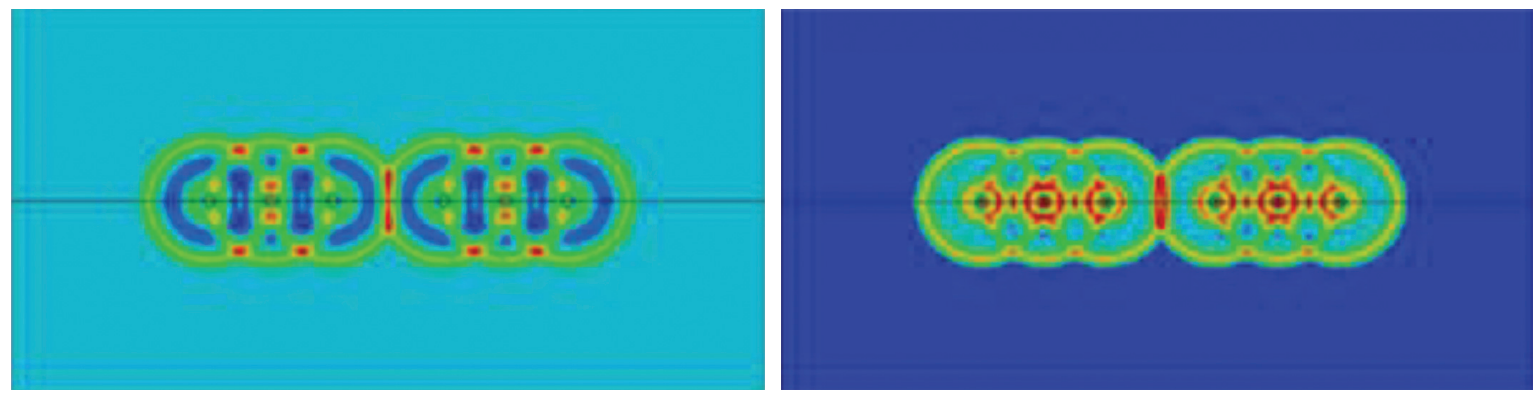

(a)
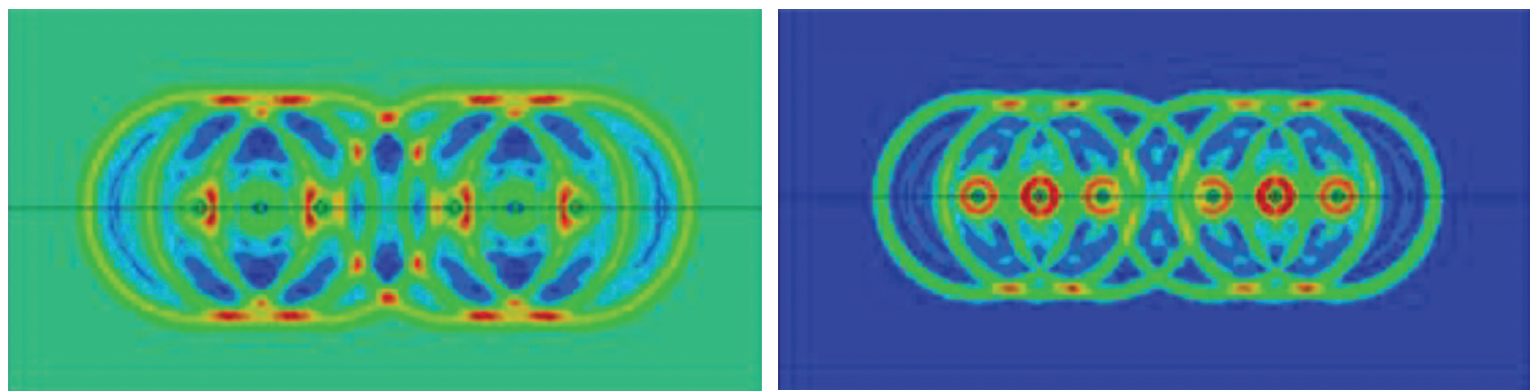

(b)
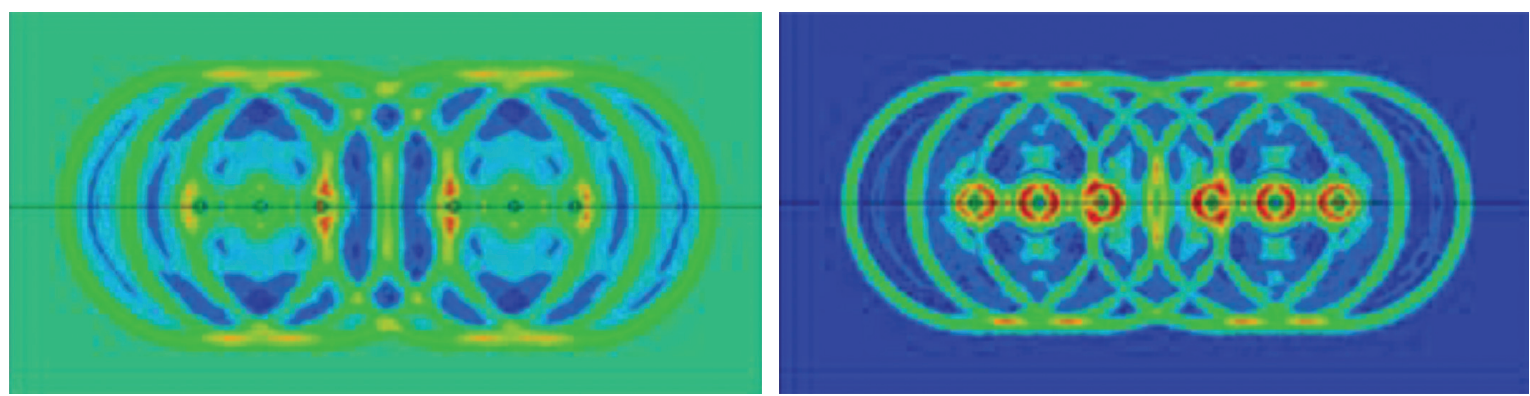

(c)

Figure 19: The evolution of the effective stress in the surrounding rock with the borehole spacing of $8 \mathrm{~m}$ at different times. (a) $T=3.5 \mathrm{~ms}$. (b) $T=5.5 \mathrm{~ms}$. (c) $T=7.0 \mathrm{~ms}$.

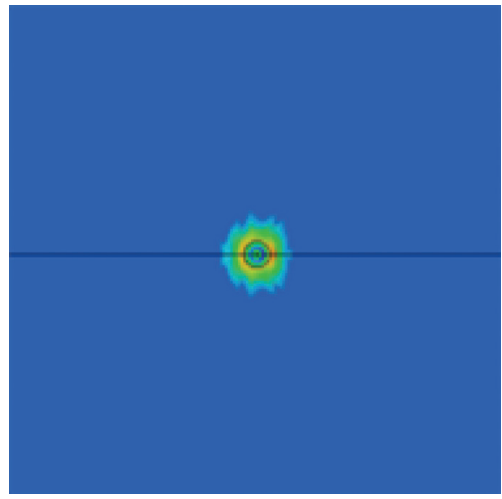

(a)

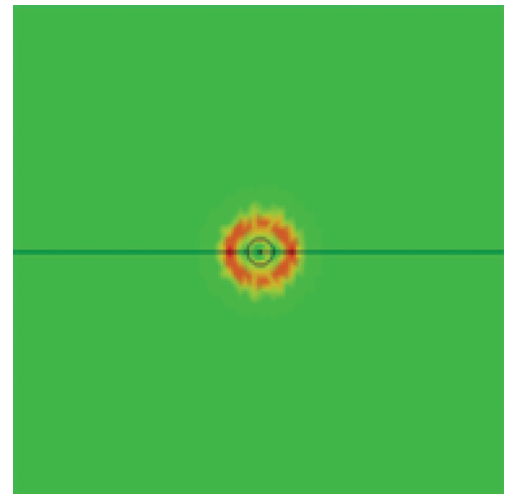

(b)

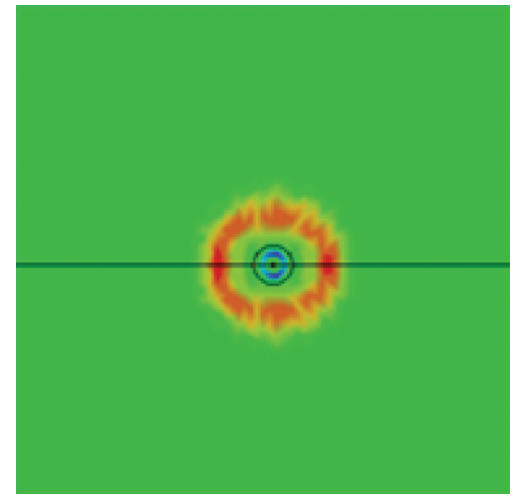

(c)

FIgURe 20: Continued. 


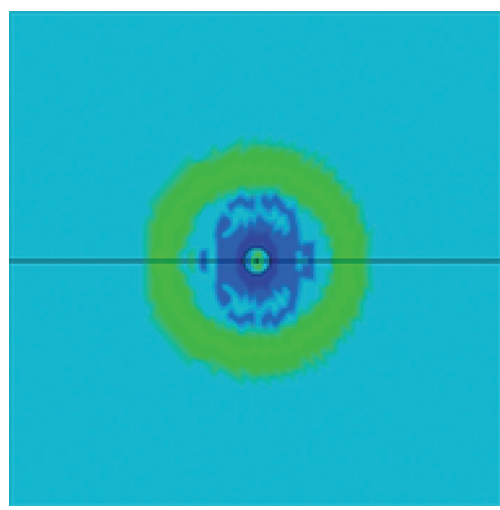

(d)

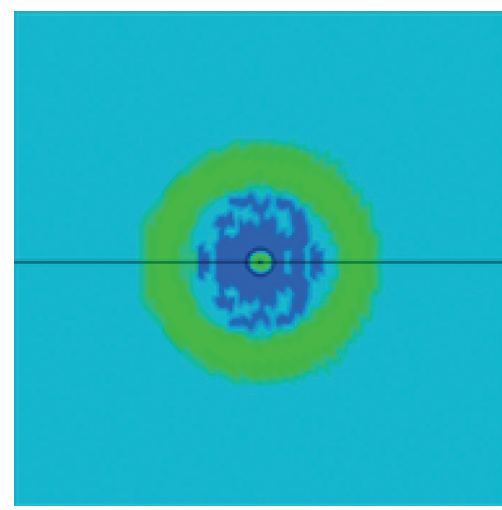

(e)

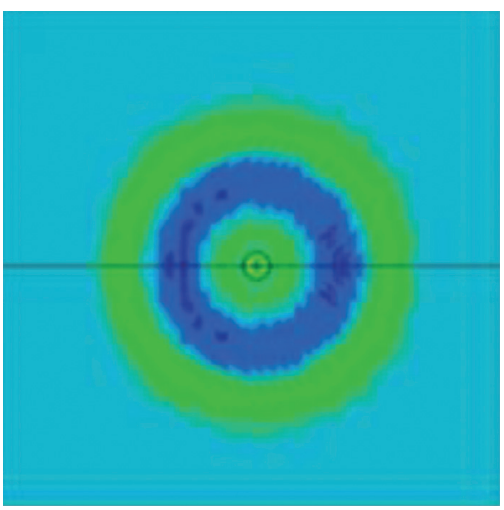

(f)

Figure 20: The evolution of the effective stress in the surrounding rock without split at different times. (a) $T=0.58 \mathrm{~ms}$. (b) $T=1.0 \mathrm{~ms}$. (c) $T=1.42 \mathrm{~ms}$. (d) $T=2.0 \mathrm{~ms}$. (e) $T=2.50 \mathrm{~ms}$. (f) $T=3.30 \mathrm{~ms}$.

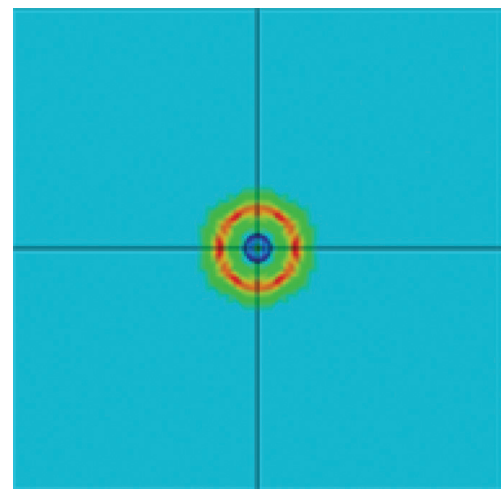

(a)

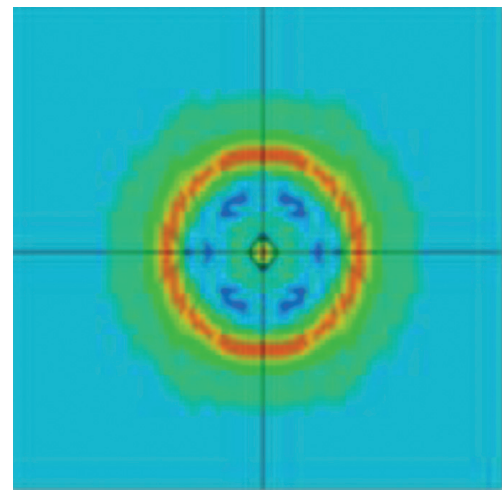

(d)

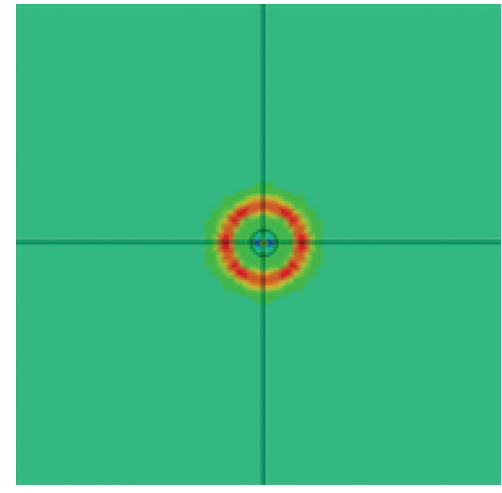

(b)

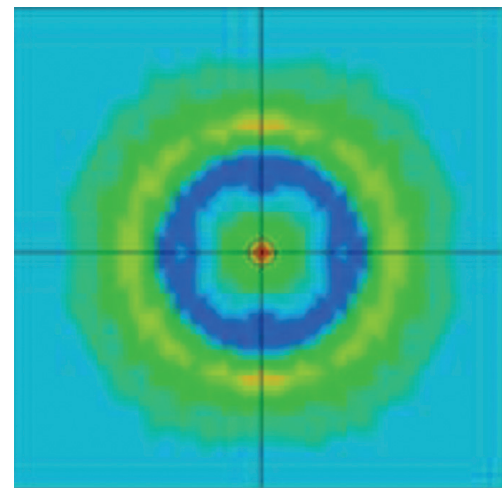

(e)

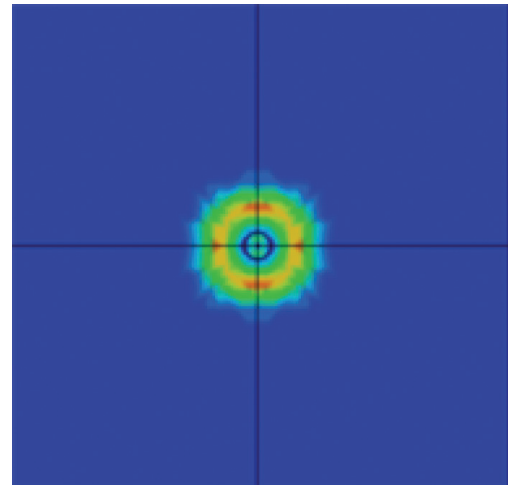

(c)

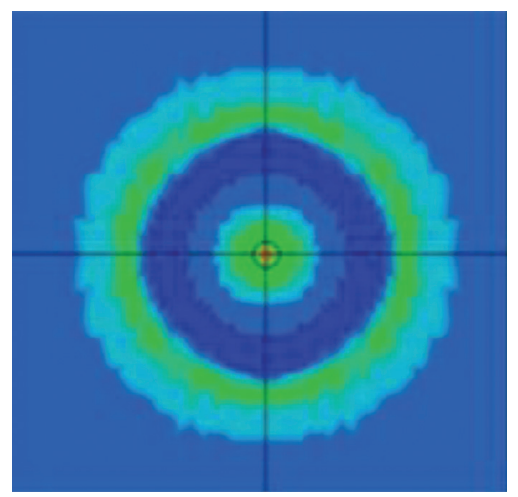

(f)

Figure 21: The evolution of the effective stress in the surrounding rock with a split spacing of $15 \mathrm{~mm}$ at different times. (a) $T=0.60 \mathrm{~ms}$. (b) $T=1.00 \mathrm{~ms}$. (c) $T=1.50 \mathrm{~ms}$. (d) $T=2.00 \mathrm{~ms}$. (e) $T=2.51 \mathrm{~ms}$. (f) $T=3.32 \mathrm{~ms}$. 


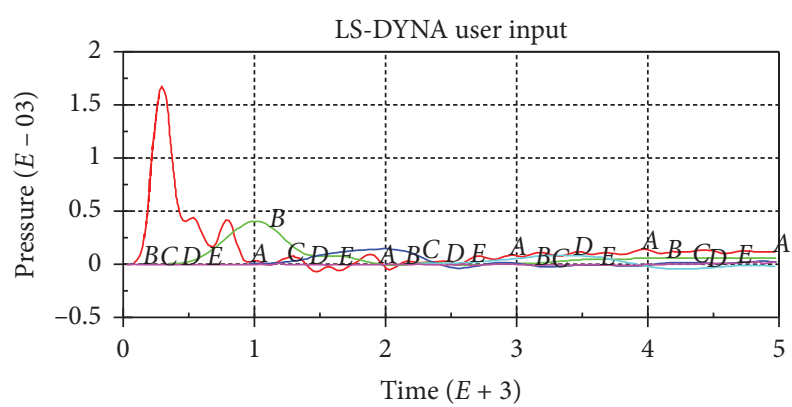

Element no.

\begin{tabular}{llll}
$\frac{A}{B}$ & 40 & $\frac{D}{E}$ & 244 \\
$C$ & 64 & - & 214 \\
\hline & 91 & &
\end{tabular}

(a)

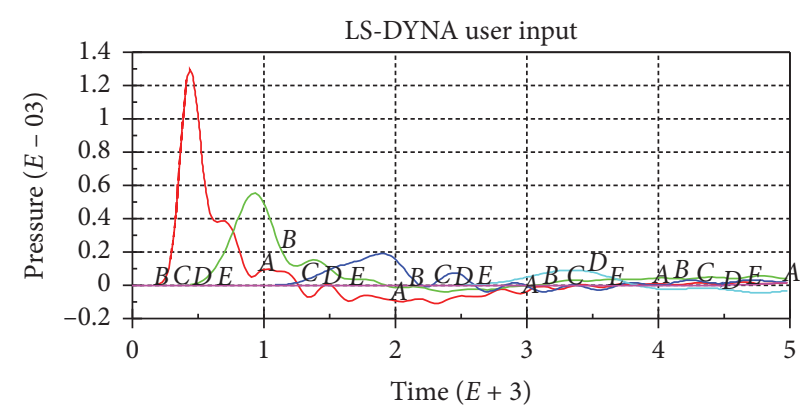

Element no.

$\begin{array}{llll}\frac{A}{B} & 61 & \frac{D}{E} & 241 \\ C & 91 & & \\ C & 156 & & \end{array}$

(b)

FIgURE 22: The effective stress obtained from different monitoring points with or without the presplit technique.
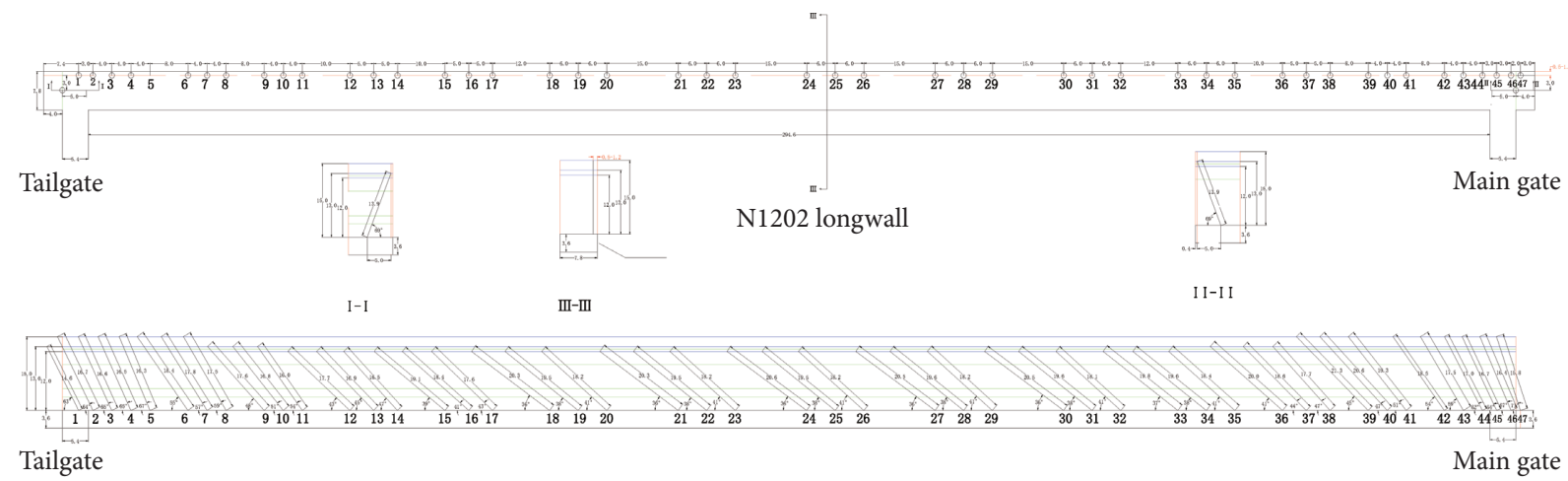

FIgURE 23: Layout of the blast boreholes in the N1202 longwall.

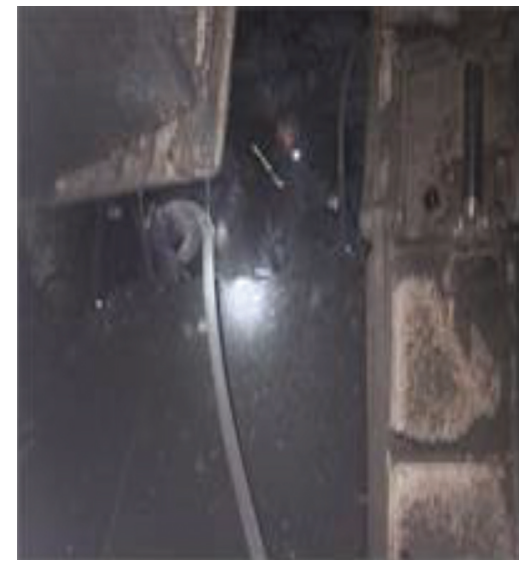

(a)

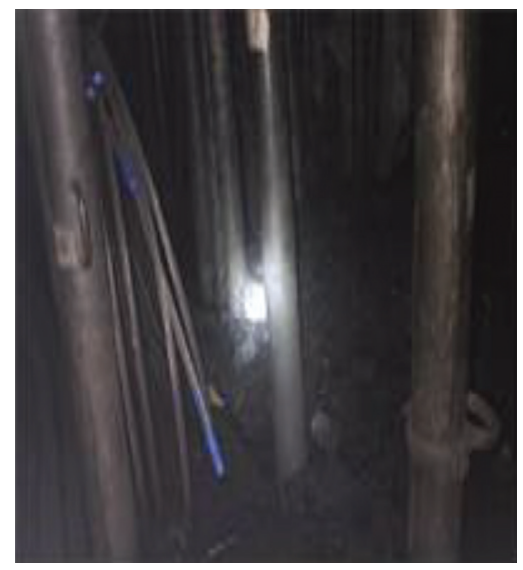

(b)

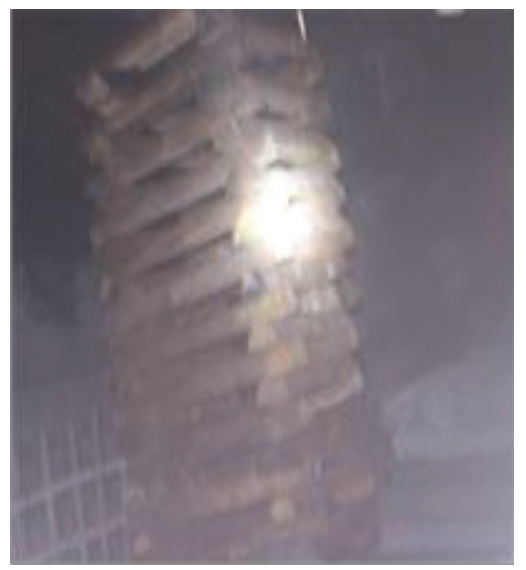

(c)

FIgURE 24: Roof deformation with the application of the presplit blasting technique. (a) Working face. (b) Main gate. (c) Tailgate. 

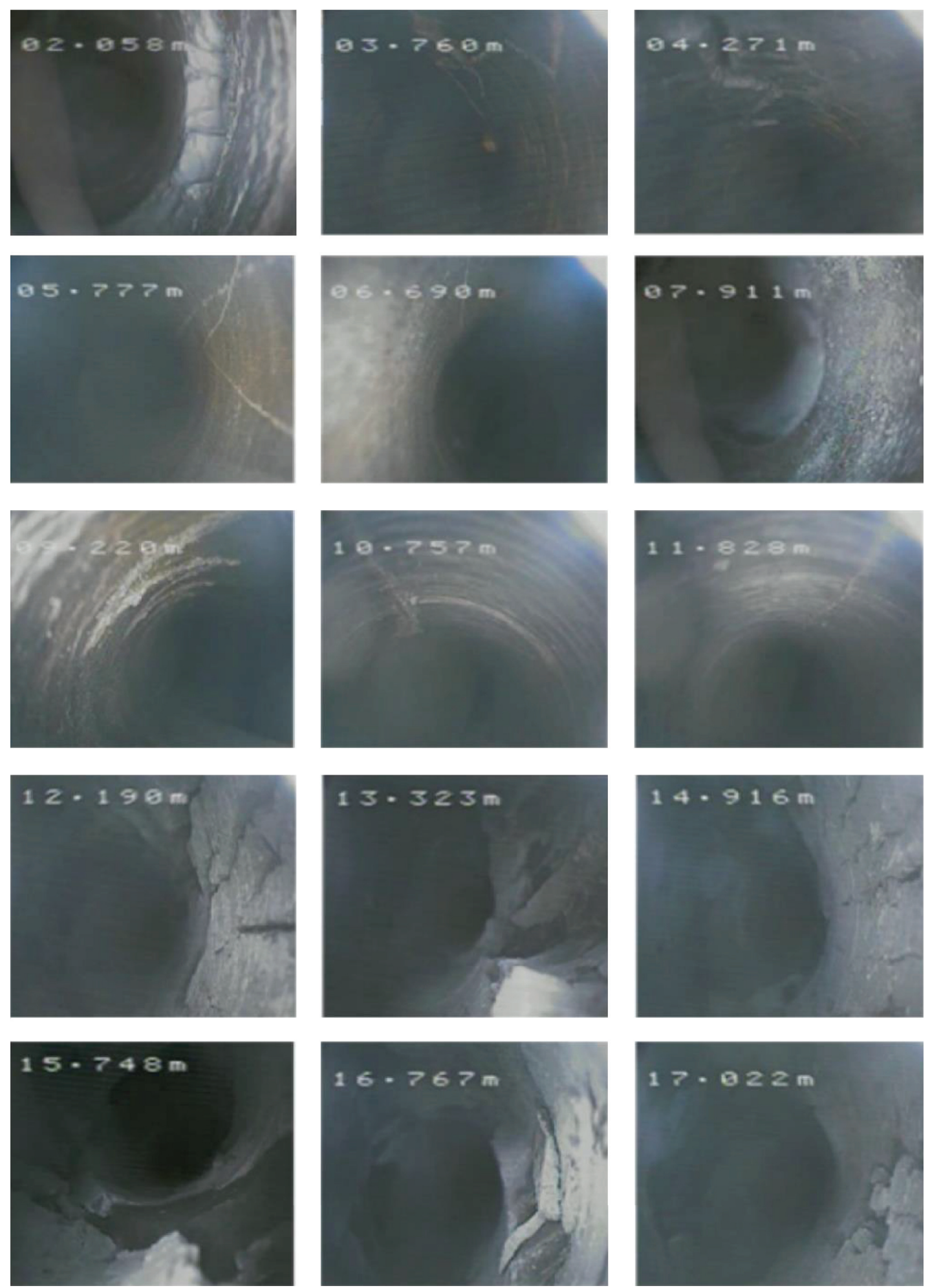

FIGURE 25: The inner surface of the surrounding rock in the blast borehole. 


\section{Conclusions}

The hanging of the hard overlying strata is believed to be one of the main reasons for the occurrence of the dynamic accident. This paper presents the case study of the application of presplit blasting technique in treating the predriving roadway through the longwall with the hard overlying strata. The following conclusions can be drawn based on the discussions in the present research:

(1) Compared with the conventional layout of the blasting hole, the effect of the noncoupling coefficient is much obvious. With the increase of the noncoupling coefficient, the diameter of the crushed zone decreased, whereas the dimeter of fractured zone experience somewhat increase.

(2) Both the blasting borehole spacing and the split width will significantly affect the distribution of the stress and radius of the crushed zone and fracture zone. When other parameters are the same, the smaller borehole spacing and split width are highly recommended to reduce the radius of the crushed zone.

(3) The advantages of the presplit blasting technique have been verified by the field study in weakening the large-scale predriving roadway with the hard overlying strata. The length of the hard roof block has been significantly decreased, which is the direct evidence to support the effectiveness of the presplit technique.

Note that the rock mass is generally regarded as a homogeneous medium in numerical calculation. However, there must be a lot of joints and fissures in practical engineering. Therefore, the critical parameters obtained from numerical simulation should be further verified by the field case study.

\section{Data Availability}

The research data used to support the findings of this study are currently under embargo while the research findings are commercialized. Requests for data, 12 months after publication of this article, will be considered by the corresponding author.

\section{Conflicts of Interest}

The authors declare that they have no conflicts of interest regarding the publication of this paper.

\section{Acknowledgments}

The authors acknowledge the financial support provided by the Key Research Programme (High-Tech) of Shanxi Province (201903D121075) and the Transformation of Scientific Technological Achievement Programme of Higher Education Institutions in Shanxi (JYT2019015).

\section{References}

[1] P. Yiouta-Mitra and A. I. Sofianos, "Multi-jointed stratified hard rock roof analysis and design," International Journal of Rock Mechanics and Mining Sciences, vol. 106, 2018.

[2] J. Hu, M. He, J. Wang, Z. Ma, Y. Wang, and X. Zhang, "Key parameters of roof cutting of gob-side entry retaining in a deep inclined thick coal seam with hard roof," Energies, vol. 12, no. 5, p. 934, 2019.

[3] G. S. Esterhuizen, I. B. Tulu, D. F. Gearhart, H. Dougherty, and M. van Dyke, "Assessing support alternatives for longwall gateroads subject to changing stress," International Journal of Mining Science and Technology, vol. 31, 2021.

[4] Y. L. Tan, X. S. Liu, B. Shen, J. G. Ning, and Q. H. Gu, "New approaches to testing and evaluating the impact capability of coal seam with hard roof and/or floor in coal mines," Geomechanics and Engineering, vol. 14, no. 4, pp. 367-376, 2018.

[5] H. Li and H. Li, "Mechanical properties and acoustic emission characteristics of thick hard roof sandstone in Shendong coal field," International Journal of Coal Science \& Technology, vol. 4, no. 2, pp. 147-158, 2017.

[6] S. Zhang, Y. Li, B. Shen, X. Sun, and L. Gao, "Effective evaluation of pressure relief drilling for reducing rock bursts and its application in underground coal mines," International Journal of Rock Mechanics and Mining Sciences, vol. 114, 2019.

[7] Z. Khademian and O. Ugur, "Computational framework for simulating rock burst in shear and compression," International Journal of Rock Mechanics and Mining Sciences, vol. 110, 2018.

[8] J. Liu, C. Liu, Q. Yao, and G. Si, "The position of hydraulic fracturing to initiate vertical fractures in hard hanging roof for stress relief," International Journal of Rock Mechanics and Mining Sciences, vol. 132, 2020.

[9] H. Kang, L. Wu, F. Gao, H. Lv, and J. Li, "Field study on the load transfer mechanics associated with longwall coal retreat mining," International Journal of Rock Mechanics and Mining Sciences, vol. 124, 2019.

[10] D. Tuncay and T. Klemetti, "Investigating different methods used for approximating pillar loads in longwall coal mines," International Journal of Mining Science and Technology, vol. 31, 2020.

[11] A. N. Dehghan, "An experimental investigation into the influence of pre-existing natural fracture on the behavior and length of propagating hydraulic fracture," Engineering Fracture Mechanics, vol. 240, 2020.

[12] Z. Zhang, N. Zhang, H. Shimada, T. Sasaoka, and S. Wahyudi, "Optimization of hard roof structure over retained goaf-side gateroad by pre-split blasting technology," International Journal of Rock Mechanics and Mining Sciences, vol. 100, 2017.

[13] Y. Shang, J. Wang, X. Li, J. Ning, and P. Qiu, "In situ investigations into mining-induced hard main roof fracture in longwall mining: a case study," Engineering Failure Analysis, vol. 106, 2019.

[14] C.-P. Lu, Y. Liu, G.-J. Liu, and T.-B. Zhao, "Stress evolution caused by hard roof fracturing and associated multi-parameter precursors," Tunnelling and Underground Space Technology, vol. 84, 2019.

[15] B. Huang, J. Liu, and Q. Zhang, "The reasonable breaking location of overhanging hard roof for directional hydraulic fracturing to control strong strata behaviour of gob-side entry," International Journal of Rock Mechanics and Mining Sciences, vol. 103, 2018.

[16] A. Movassagh, M. Haghighi, X. Zhang, D. Kasperczyk, and M. Sayyafzadeh, "A fractal approach for surface roughness 
analysis of laboratory hydraulic fracture," Journal of Natural Gas Science and Engineering, vol. 85, 2021.

[17] Q. He, F. T. Suorineni, T. Ma, and J. Oh, "Parametric study and dimensional analysis on prescribed hydraulic fractures in cave mining," Tunnelling and Underground Space Technology, vol. 78, 2018.

[18] X. Huo, X. Shi, X. Qiu et al., "Rock damage control for largediameter-hole lateral blasting excavation based on charge structure optimization," Tunnelling and Underground Space Technology, vol. 106, 2020.

[19] K. Liu, Q. Li, C. Wu, X. Li, and J. Li, "Optimization of spherical cartridge blasting mode in one-step raise excavation using pre-split blasting," International Journal of Rock Mechanics and Mining Sciences, vol. 126, 2020.

[20] R. Gao, B. Huo, H. Xia, and X. Meng, "Numerical simulation on fracturing behaviour of hard roofs at different levels during extra-thick coal seam mining," Royal Society Open Science, vol. 7, no. 1, p. 191383, 2020.

[21] H. P. Kang and Y. J. Feng, "Role of borehole transverse notching on hydraulic fracturing in hard rock," in ISRM SINOROCK 2013International Society for Rock Mechanics and Rock Engineering, Lisbon, Portugal, 2013.

[22] ASTM D7012-10, Standard Test Method for Compressive Strength and Elastic Moduli of Intact Rock Core Specimens under Varying States of Stress and Temperatures, ASTM, West Conshohocken, PA, USA, 2013.

[23] M. Qian, X. Miao, and F. He, "Analysis of key block in the structure of voussoir beam in longwall mining," International Journal of Rock Mechanics and Mining Sciences and Geomechanics Abstracts, vol. 4, no. 32, p. 191A, 1995.

[24] Y. D. Murray, Users Manual for LS-DYNA Concrete Material Model 159 (No. FHWA-HRT-05-062), Federal Highway Administration, Washington, DC, USA, 2007. 